UNIVERSITE DU QUEBEC

MEMOIRE PRÉSENTÉ À

L'UNIVERSITÉ DU QUÉBEC À CHICOUTIMI

COMME EXIGENCE PARTIELLE

DE LA MAÎTRISE EN INGÉNIERIE

Par

Maryam Ghalkhani

Contribution to the Improvement of the Dissolved Gas

Analysis Techniques

Contribution à 1'Amélioration des Techniques de Diagnostics par Analyse des Gaz Dissous

October 2012 


\section{Abstract}

There is a general agreement that in service conditions the quality of mineral insulating oils gradually deteriorates under the impact of electrical, thermal and environmental stresses. It is also widely accepted that only the incipient electrical failures such as hot spots and partial discharges are responsible for the gassing of oil. Knowing that the resulting fault gases dissolve in the oil, the technique of Dissolved Gas Analysis (DGA) was developed to detect incipient failures in the transformer. DGA has now become a standard in the utility industry throughout the world and is considered to be the most important oil test for insulating liquids in electrical apparatus. More importantly, an oil sample can be taken at anytime from most equipment without having to take it out of service, allowing a "window" inside the electrical apparatus that helps with diagnosing and trouble-shooting potential problems. This thesis intends to show that the gassing of oil is a more complex phenomenon.

In order to emphasize the role played by contaminants in the gassing of oil, fundamental investigations were undertaken. The amount of gases evolved under the impact of electrical stress (ASTM D6180) by a sample of new and aged oil with/without paper was accurately measured along with some physicochemical properties, to assess the relationship between the cause and the symptoms of oil or oil-paper insulation deterioration. The outcome of these investigations provided experimental evidence that the chemical composition of hydrocarbon blend, the oil born decay products and the solid insulation are also contributing factors to oil gassing. Since this finding may affect the diagnostics predicted by some DGA techniques, some thorough investigations were performed. New, aged oil and reclaimed aged oil samples were submitted to thermal and electrical stresses (considering various scenarios) and the dissolved gases analyzed by chromatography. Three of the most used DGA techniques, namely the Duval's Triangle Roger's and Dörnenburg's ratios were implemented in Labview based software to predict the diagnostic. The obtained results provide experimental evidence that oil born decay products may affect the diagnostics predicted by some DGA techniques. Although such a research is still in a preliminary stage, some very stimulating results have been obtained. 


\section{Résumé}

Il est généralement admis, qu'en conditions de service, la qualité des huiles minérales isolantes se détériore progressivement sous l'effet des contraintes électriques, thermiques et environnementales. Il est également largement admis que seules les défaillances électriques naissantes telles que les points chauds et les décharges partielles sont responsables du dégazage de l'huile. Sachant que les gaz ainsi produits par les défauts se dissolvent dans l'huile, la technique d'analyse de gaz dissous (AGD) a été mise au point pour détecter les défaillances dans le transformateur. L'AGD est maintenant devenu un standard dans l'industrie à travers le monde et elle est considérée comme le test le plus important dans les appareillages électriques isolés à l'huile. Plus important encore, un échantillon d'huile peut être pris à tout moment, de la plupart des équipements, sans avoir à le mettre hors service, pour le diagnostic et le dépannage d'éventuels problèmes. Ce mémoire se propose de montrer que le gazage dans l'huile est un phénomène complexe.

Afin de souligner le rôle joué par les contaminants dans le dégazage de l'huile, des investigations fondamentales ont été entreprises. La quantité de gaz qui se dégage sous l'effet de la contrainte électrique (ASTM D6180) d'un échantillon d'huile neuf ou vieilli avec/sans papier a été mesurée avec précision ainsi que certaines propriétés physico-chimiques, afin d'évaluer la relation entre la cause et les effets de la détérioration de l'isolation de l'huile ou de 1'huile-papier. Le résultat de ces investigations a fourni des preuves expérimentales que la composition chimique d'un mélange d'hydrocarbures, les produits issus de la décomposition de l'huile et de l'isolation solide sont également des facteurs qui contribuent à la génération de gaz dans 1'huile. Étant donné que cette découverte pourrait affecter les diagnostics prédits par certaines techniques de l'ADG, certaines investigations approfondies ont été réalisées. Des échantillons d'huile neuve, âgée et régénérée ont été soumis à des contraintes thermiques et électriques (en considérant différents scénarios) et les gaz dissous analysés par chromatographie. Trois des techniques de l'ADG les plus utilisées à savoir le Triangle de Duval, Roger et le Ratio de Dörnenburg ont été implémentées dans le logiciel Labview pour prédire le diagnostic. Les résultats obtenus fournissent la preuve expérimentale que les produits de la décomposition de l'huile peuvent affecter les résultats de diagnostic prédis par certaines 
techniques de l'ADG. Bien qu'une telle recherche soit encore à un stade préliminaire, certains résultats encourageants ont été obtenus. 


\title{
Dedicated to:
}

\author{
My loving and supportive family: \\ My beloved parents, Allah Bakhash and Nahid \\ My lovely sister and Brother, Parvin and Reza \\ $\&$ \\ My dear husband Sayyed Mahdi
}




\section{Acknowledgments}

To start with, I am thankful to almighty providence, God, who lends me life, the faith and for all mercies he has blessed me greatly in all the work, specially my kind spouse.... I am most grateful for having the opportunity to continue my education in the Master's research program offered by UQAC.

I would like to thank hearty Prof. I. Fofana, my director for his support, supervision, guidance, encouragement, motivation and patience in this endeavor. I will forever be indebted to him for showing his interest, generous help during my Master's studies, Special thanks to Dr. H. Hemmatjou, my co-director and mentor for his patience and guidance. I am particularly grateful for all of his time and help during last two years.

I am also grateful to Dr. H. Ezzaidi and Dr. Fethi Meghnefi for accepting to be jury members and for their constructive criticism which contributed to improve the quality of this thesis.

I would like to express my thanks to Dr. Janvier Sylvestre N'CHO from Institut National Polytechnique Félix HOUPHOUËT-BOIGNY, for his valuable comments during my evaluation thesis.

Most importantly, none of this would have been possible without the love and patience of my family. I want to extend my warmest thanks to my parents, sister and brother for all the love, support, advice and encouragement they have given me. I can't express my gratitude for my mom in words, whose unconditional love has been my greatest strength. I am especially grateful to them for teaching me to be ambitious and for always believing in me throughout my life.

Last but not least, I would like to express my deepest gratitude to my beloved husband, Sayyed Mahdi Ale Emran, for his true love and patience. He has always found the right words to cheer me up and his faith in me gave me strength to carry on. I look forward to my future with him and to more great moments. 


\section{Table of Contents}

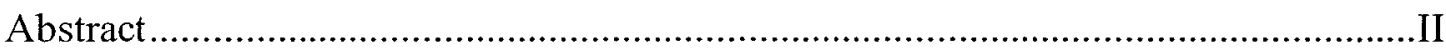

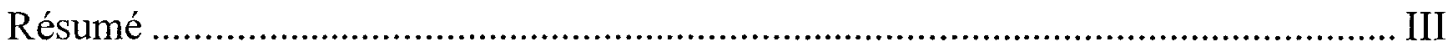

Acknowledgments ......................................................................................... VI

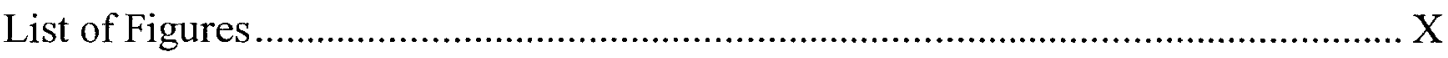

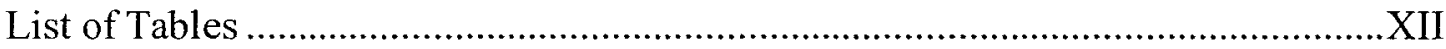

Abbreviations and Symbols .............................................................................. XIII

\section{Chapter 1}

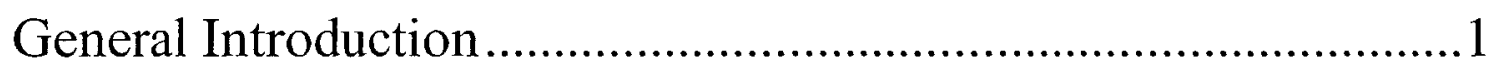

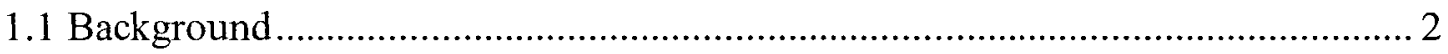

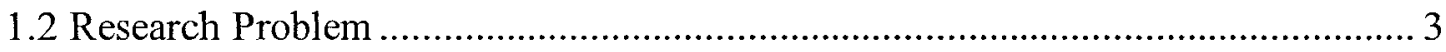

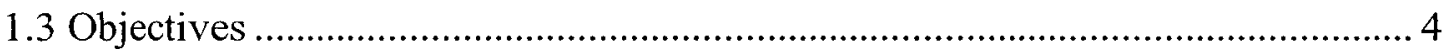

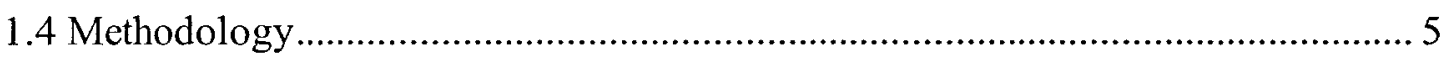

1.4.1 Dehydratation system (degassing and dehumidification) .......................... 5

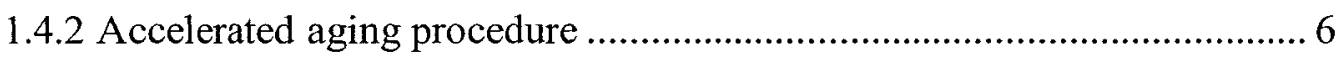

1.4.3 Water Content (ASTM D 1533): ………………….......................... 7

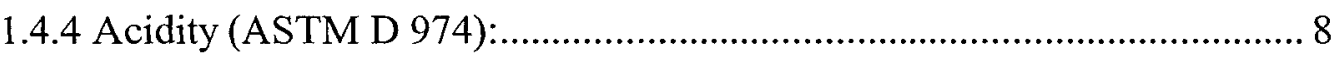

1.4.5 Interfacial Tension (ASTM D 971): ...................................................... 9

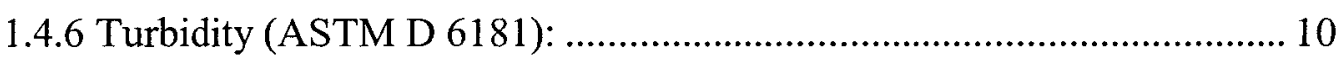

1.4.7 Dissolved Decay Product (ASTM D 6802):.............................................. 10

1.4.8 Partial discharge: .............................................................................. 11

1.4.9 AC breakdown discharge (ASTM D 877):............................................ 11

1.4.10 Dissolved Gas Analysis (ASTM D 3612A): ......................................... 12

1.4.11 Stability test for mineral insulating Oils (ASTM D 6180-05) ................ 13

1.5 Statement of the originality of the thesis .............................................................. 14

1.6 Overview of the Thesis .................................................................................. 15 


\section{Chapter 2}

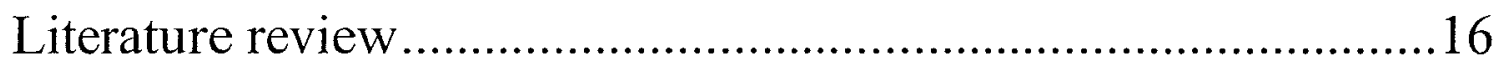

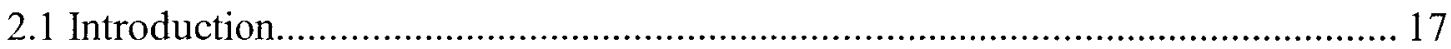

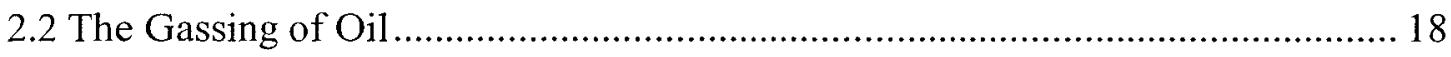

2.2.1 DGA most used Interpretation Techniques ………………………….... 22

2.2.2 Traditional DGA methods .................................................................... 23

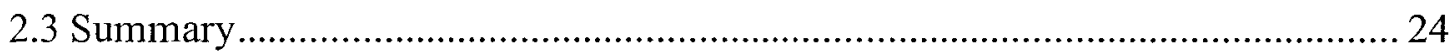

\section{Chapter 3}

Implementation of some methods in Labview ............................25

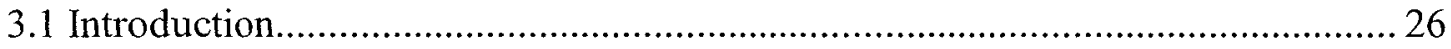

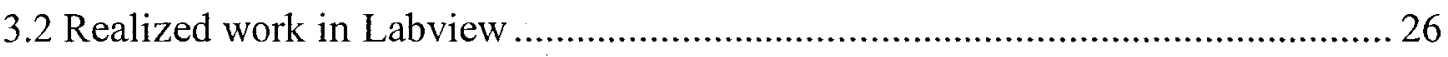

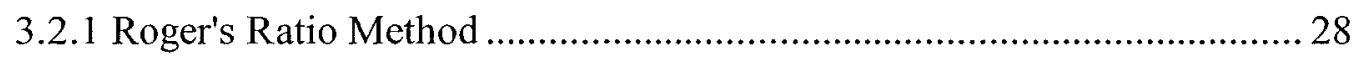

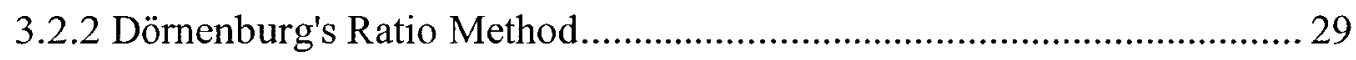

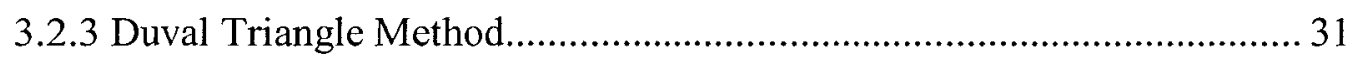

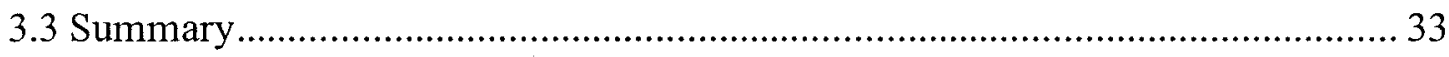

\section{Chapter 4}

Gassing stability of oil and complex oil-paper system under electrical

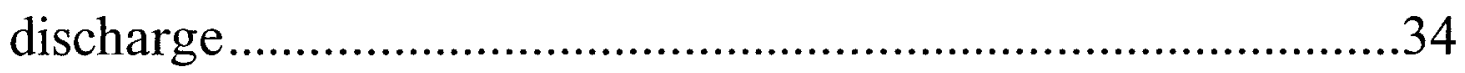

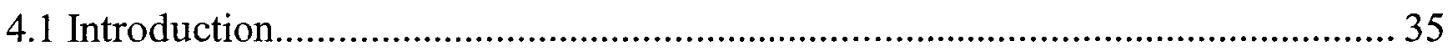

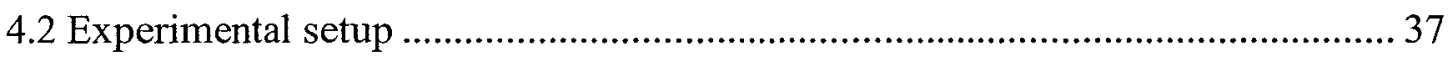

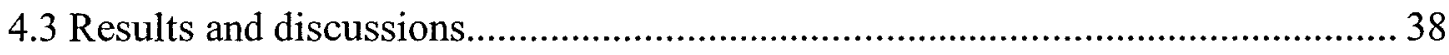

4.3.2 Dissolved Decay Product (DDP) .......................................................... 41

4.3.3 Interfacial tension (IFT) ....................................................................... 43

4.3.4 Water content in transformer oil............................................................ 43

4.4 Summary 


\section{Chapter 5}

Impact of aging by-products on DGA techniques.........................46

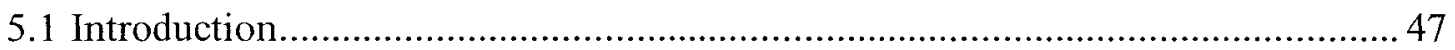

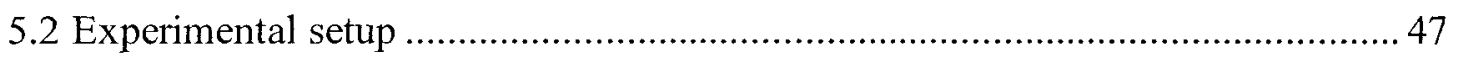

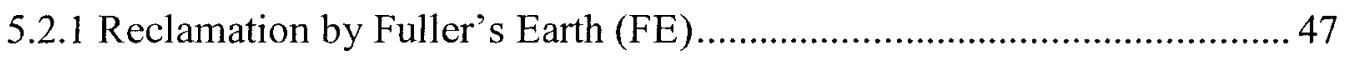

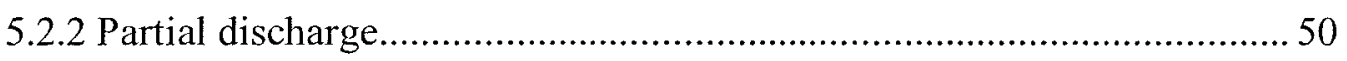

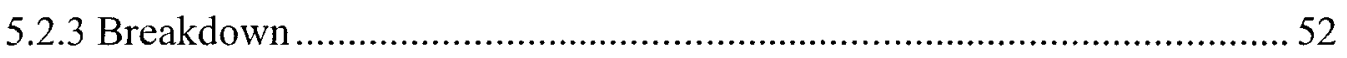

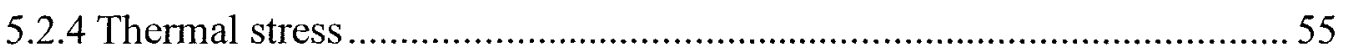

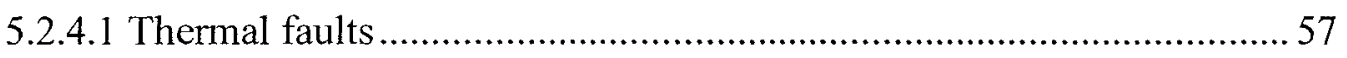

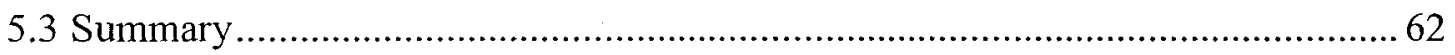

\section{Chapter 6}

Conclusions and Recommendations............................................63

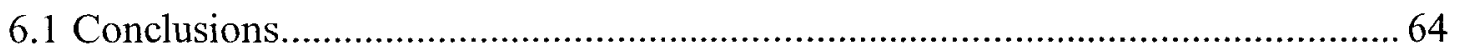

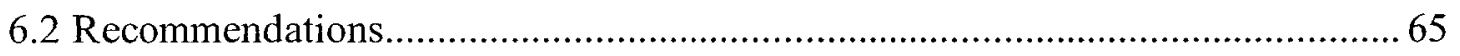

References...............................................................66 


\section{List of Figures}

Figure 1.1. Two-stage drying and degassing unit developed at UQAC .............................. 6

Figure 1.2. Mechanical Convection (Model DKN-900). ................................................. 7

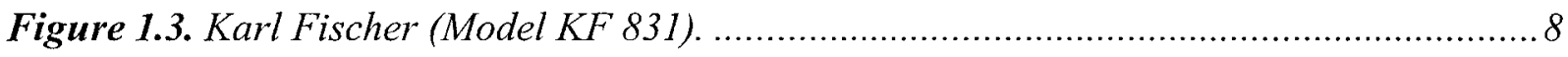

Figure 1.4. Setup for measuring the acidity of liquid ................................................. 9

Figure 1.5. Tensiometer for measuring the interfacial tension of a liquid............................ 9

Figure 1.6. Turbidity meter for measuring cloudiness of liquid..................................... 10

Figure 1.7. Spectrophotometer for measuring the relative dissolved decay products in oil ...10

Figure 1.8. Test cell of partial discharge test. ...................................................... 11

Figure 1.9. Model LD75 liquid dielectric test set .................................................... 12

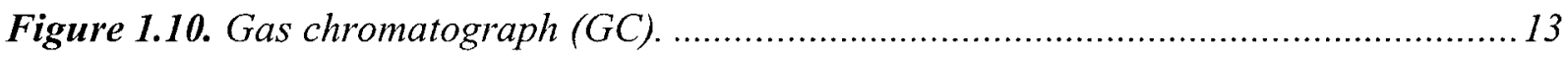

Figure 2.1. Functional based classification of oil properties [4] ................................17

Figure 2.2. Potential causes of insulating liquid gassing............................................. 19

Figure 2.3. The decomposition of oil/paper caused by incipient failures [21] .....................20

Figure 2.4. Sketch of insulating oil decaying processes, inside a free breathing power

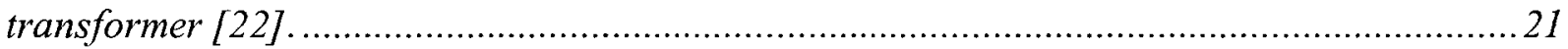

Figure 3.1. Overview of the Main interface of the Labview program. ................................2 27

Figure 3.2. Block diagram of the program............................................................ 28

Figure 3.3. Implementation of Roger's method in Labview............................................29

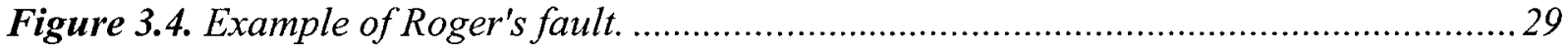

Figure 3.5. Dörnenburg's ratio method in Labview....................................................... 30

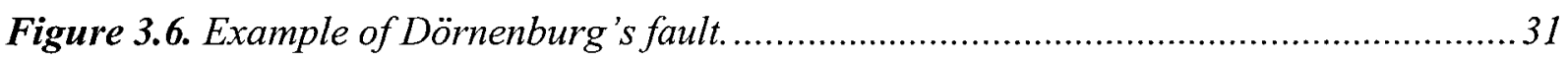

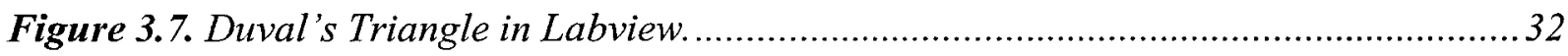

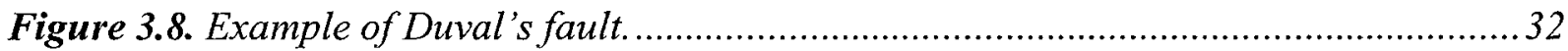

Figure 4.1. Discharge cell according to ASTM Designation D6180 [10]............................ 37

Figure 4.2. The gassing tendency of new and aged oil samples without paper.................... 38

Figure 4.3. The gassing tendency of combined aged oil-paper (with and without paper)......39

Figure 4.4. The gassing tendency of new and aged oil with $10 \%$ of paper as per D6180.....39

Figure 4.5. The gassing tendencies of new and aged oil samples with $30 \%$ of paper, according to $D 6180$. 
Figure 4.6. Comparison of Turbidity (D6181) before \& after D6180 stability test. 41

Figure 4.7. Absorbance illustrating the Dissolved Decay Products of new oil before and after D6180. 41

Figure 4.8. Absorbance illustrating the Dissolved Decay Products of new oil and aged (500 h, $1000 \mathrm{~h}$ and $2000 \mathrm{~h}$ ) oil before and after D6180. 42

Figure 4.9. Water content assessment in oil sample before and after D6180. .44

Figure 5.1. Comparative summary of $1000 \mathrm{~h}$ aged oil properties before and after reclamation.

Figure 5.2. Summary of the fluids properties after Partial discharge application.................52

Figure 5.3. Test vessel and setup for local heating of the insulating liquid [35] .................56

Figure 5.4. Comparative summary of the fluids properties after Thermal test $(20 \mathrm{~A})$..........60

Figure 5.5. Comparative summary of the fluids properties after Thermal test ( $3 \mathrm{~A})$. 61 


\section{List of Tables}

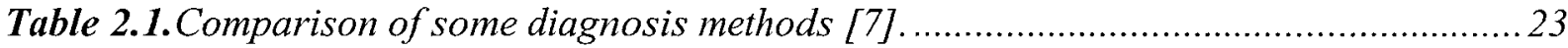

Table 3.1. Roger's Ratio Method ............................................................................... 28

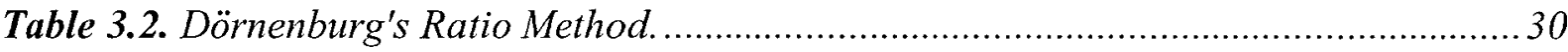

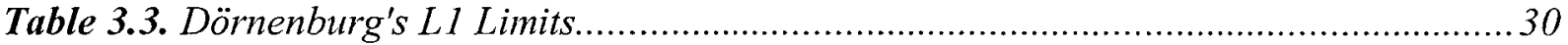

Table 4.1. DDP results for new and aged oil samples before and after D6180 ..................42

Table 4.2. IFT results assessments before and after D6180 ...................................... 43

Table 4.3. Insulating fluid samples assessment before D6180 stability test. ....................... 45

Table 4.4. Insulating fluid samples assessment after D6180 stability test........................... 45

Table 5.1.Dissolved gas extracted from the samples before \& after reclamation................. 48

Table 5.2. Summary the oil properties before reclamation process...................................... 49

Table 5.3. Dissolved gases extracted from the samples after application of PD ...................50

Table 5.4. DGA diagnostic assessment's after application of partial discharge. ................... 50

Table 5.5. Dissolved gases extracted from the samples after application of PD..................5I

Table 5.6. DGA diagnostic assessment's after application of partial discharge stress..........51

Table 5.7. Summary of the fluids properties submitted to partial discharge stress...............51

Table 5.8. Dissolved gases extracted from the samples after application of 50 breakdown tests. 53

Table 5.9. DGA after application of 50 breakdown tests in the oil samples. 53

Table 5.10. Dissolved gases extracted from the samples after application of 50 breakdown tests. 54

Table 5.11. DGA results after application of 50 breakdown tests in the oil samples............. 54

Table 5.12. Some oil properties submitted to breakdown test before and after reclamation... 55

Table 5.13. Dissolved gases extracted from the samples after thermal stress (20 A) ............58

Table 5.14. DGA after application of Thermal $(20 \mathrm{~A})$ test in the oil samples........................ 58

Table 5.15. Dissolved gases extracted from the samples submitted to Thermal stress (20 A). 59

Table 5.16. DGA after application of Thermal stress $(20 \mathrm{~A})$ to the oil samples.....................59

Table 5.17. Dissolved gases extracted from the samples after thermal stress $(3 \mathrm{~A}) \ldots \ldots \ldots \ldots . . .60$

Table 5.18. DGA assessment's after application of Thermal (3A) test in the oil samples......61 


\section{Abbreviations and Symbols}

DGA

Dissolved Gas Analysis

IEEE

Institute of Electrical and Electronics Engineers

ASTM

American Society for Testing and Materials

TAN

Total Acid Number

IFT

Interfacial tension

NTU

Nephelometric Turbidity Units

DDP

Dissolved Decay Product

PDIV

Partial Discharge Inception Voltage

DP

Degree of Polymerization

2-FAL

Furfuraldehyde

FTIR

Fourier Transform Infrared

ANNs

Artificial Neural Networks

RRM

Roger's Ratio Method

DRM

Dörnenburg's Ratio Method

KGM

Key Gas Method

$\mathrm{NN}$

Neutral Number

MIN

Myers Index Number

OQIN

Oil Quality Index Number 
Chapter 1

General Introduction 


\section{Chapter 1 \\ General Introduction}

\subsection{Background}

Power transformers are important and one of the costliest equipments used in the transmission and distribution of the electric energy. Despite great progresses in power equipment design in recent years, the weak link in the chain still remains the insulation system. When power transformers fail, the fault can be traced usually to defective insulation [1-2]. Unexpected failures cause major disturbances to operating systems, resulting in unscheduled outages and power delivery problems. Extreme reliability is demanded of electric power distribution as when failures occur they inevitably lead to high repair costs, long downtime and possible personnel safety risks. In addition, environmental aspects such as consequential damages, fire and pollution are of high risk. Transformer failures can cost up to $\$ 15$ million, in addition to an operator's reputation. These enormous costs provide ample incentive for electric companies to ensure reliability and availability throughout the life cycle of these important assets. Early detection of problems can reduce repair costs by 75 percent and loss of revenue by 60 percent, and that annual cost savings equal to 2 percent of the price of a new transformer - i.e., approximately $\$ 40,000$ to $\$ 80,000$ - can be achieved [3]. By accurately monitoring the condition of oil, many types of faults can be detected before they become serious failures and outages. The analysis of transformer oils not only provides information about the oil, but also enables the detection of other potential problems, including contact arcing, ageing insulating paper and other latent faults and is an indispensable part of a cost efficient electrical maintenance program.

Although the cost of transformer oil represents only $5 \%$ of the total cost of a power transformer, its stability plays an important role in the safe operation and aging process of this expensive machine. While in service, both oil and solid insulation of windings undergo a slow but steady decay process under the impact of electrical, thermal, mechanical and chemical stresses. Recent studies [4] have shown that the gassing of oil has an important side effect. The breakdown of hydrocarbon chains generates not only soluble gases, as it is currently believed, but also colloidal suspensions. 
Many key analytical tests, providing a "picture" of the fluid or the solid insulation "health", have been studied, normalized in standards and finally taken as criterion for monitoring power transformers. So far, transformers still fail because of their insulation failure. Satisfying/accurate criteria have to be found to improve the issue.

\subsection{Research Problem}

The procedures used in the past to analyze gassing of transformer oil have generally been inadequate. The fundamental shortcomings of DGA are underscored by IEEE STD C57.104 [5] as follows: "Many techniques for the detection and the measurement of gases have been established. However, it must be recognized that analysis of these gases and interpretation of their significance is at this time not a science, but an art subject to variability". Further, "The result of various ASTM testing round robins indicates that the analytical procedures for gas analysis are difficult, have poor precision, and can be wildly inaccurate, especially between laboratories". Finally, "However, operators must be cautioned that, although the physical reasons for gas formation have a firm technical basis, interpretation of that data in term of the specific cause or causes is not an exact science, but is the result of empirical evidence from which rules for interpretation have been derived". About twenty DGA interpretation techniques have been developed so far [5]. Commercial packages exist that implement individually such methods. Several individual DGA users have also developed their own graphical software. Since all these methods are based on heuristic and not on scientific formulation, combined DGA diagnostic may reduce the risk of mistaken diagnostics and enhance accuracy [6].

So far, few pitfalls, that may affect the analyses, have been emphasized on DGA testing, namely [7]:

- Gases produced not as a result of incipient fault condition

- Leaking between tap changers and main tank

- Welding producing acetylene and other gases

- Out-gassing of paints and gaskets, (which are usually $\mathrm{CO}$ and $\mathrm{CO}_{2}$ )

- Galvanic reactions (i.e. steel + water $+\mathrm{O}_{2}=$ hydrogen production)

- lower voltage transformers having higher $\mathrm{CO}$ and $\mathrm{CO}_{2}$ values as a result of nonvacuum treatment, oxygen + heat 
- Stray gassing characteristics

- Contaminants produce gases

- Decomposition of additives such as passivators can produce gases as well $\left(\mathrm{H}_{2}\right.$ \& $\left.\mathrm{CO}_{2}\right)$

It is evident that new procedures for analyzing the DGA results are needed. Scientifically sustainable techniques can significantly improve the ability to determine the incipient electrical failures, maintenance requirements, and necessary replacements, help determine the need for additional spare transformers, reduce reliability risks and diminish costs.

Basically, the breakdown of certain unstable hydrocarbon molecules is dependent on two major factors: the chemical composition of the blend and the incipient electrical failures. ASTM Standard Test Method for gassing of oil assesses the behavior of new oils in brand new transformers. Hence, oil and transformer manufacturers perform this test. Although the oil is also gassing in operating conditions, neither the IEEE Guide C37.104 [8] nor the IEEE Guide C57.104 [5] requires the determination of gassing. Consequently, the cause of oil decomposition can be the inappropriate chemical composition of the oil or an incipient electrical failure.

Lately, attempts have been made to improve the situation. An alternative technique to the existing ASTM gassing test D 2300 [9] was developed. ASTM approved this test in 1998 as Designation D 6180 [10]. Unlike the test included a long time ago in the standard specification for new oils, the new one can measure the amount of gas evolved by any oil whether it is new, aged in service, reconditioned or reclaimed. Nevertheless, no commercial laboratory performs it for the same reason already mentioned. There is no market for a new test as long as it is not included in a document elaborated by a professional organization. A prompt review of these new procedures is needed.

\subsection{Objectives}

The main objective of this project is primarily aimed at understanding the mechanisms involved in the gassing phenomena of insulating fluids which are still poorly understood despite extensive work carried out. This research project involves fundamental studies on the role played by oil aging byproducts, onto the insulating liquids gassing. 
Fundamental studies using modern equipments, involving mainly optical diagnostics (turbidity, spectrophotometry,...), electrical and thermal stresses, and physico-chemical (Gas Chromatography, Acidity, Interfacial Tension, etc...) will be performed. All these works should allow emphasizing the influence of oil degradation on the DGA interpretation.

\subsection{Methodology}

To study the influence of all type of contaminant present in the oil, various scenarios were considered. Investigations were therefore performed on:

- Dehydrated and degassed new oil.

- Aged oil (of the same brand with new oil) in laboratory conditions.

- Aged oil-paper in laboratory condition.

- New oil and the same aged oil submitted to 5 hours electrical stress (using ASTM D 6180 test cell [10]).

- New oil-paper ( $30 \%$ and $50 \%$ of paper) and the same aged oil-paper (30\% and $50 \%$ of paper) submitted to 5 hours electrical stress (using ASTM D 6180 test cell [10]).

- Reclaimed (by Fuller's Earth) aged oil.

- DGA testing of oil samples before and after application of electrical and thermal stress to new oil, the same aged and reclaimed aged oil.

Fuller's Earth removes both moisture and neutralizes carboxylic acids. In the ISOLIME laboratory made-plant, oil is heated at $60{ }^{\circ} \mathrm{C}$ when passing through the activated Fuller's Earth cartridge to remove acids and impurities. The reclamation rejuvenates the transformer oil by eliminating contaminants formed due to entry of foreign particles, oxidation of oil and insulation deterioration, sludge formation, thermal cracking, etc. These oil samples were submitted to thermal and/or electrical stress, and DGA and gassing tendency investigated.

\subsubsection{Dehydratation system (degassing and dehumidification)}

In the present project, the mineral oil was degassed and dehumidified before starting the tests. The drying and degassing of the liquids took place in a two-stage drying unit developed at UQAC, which is sketched in Figure 1.1. The preparation guarantees very low gas contents of less than $0.5 \%$ and also a very low water content of less than $5 \mathrm{ppm}$. 


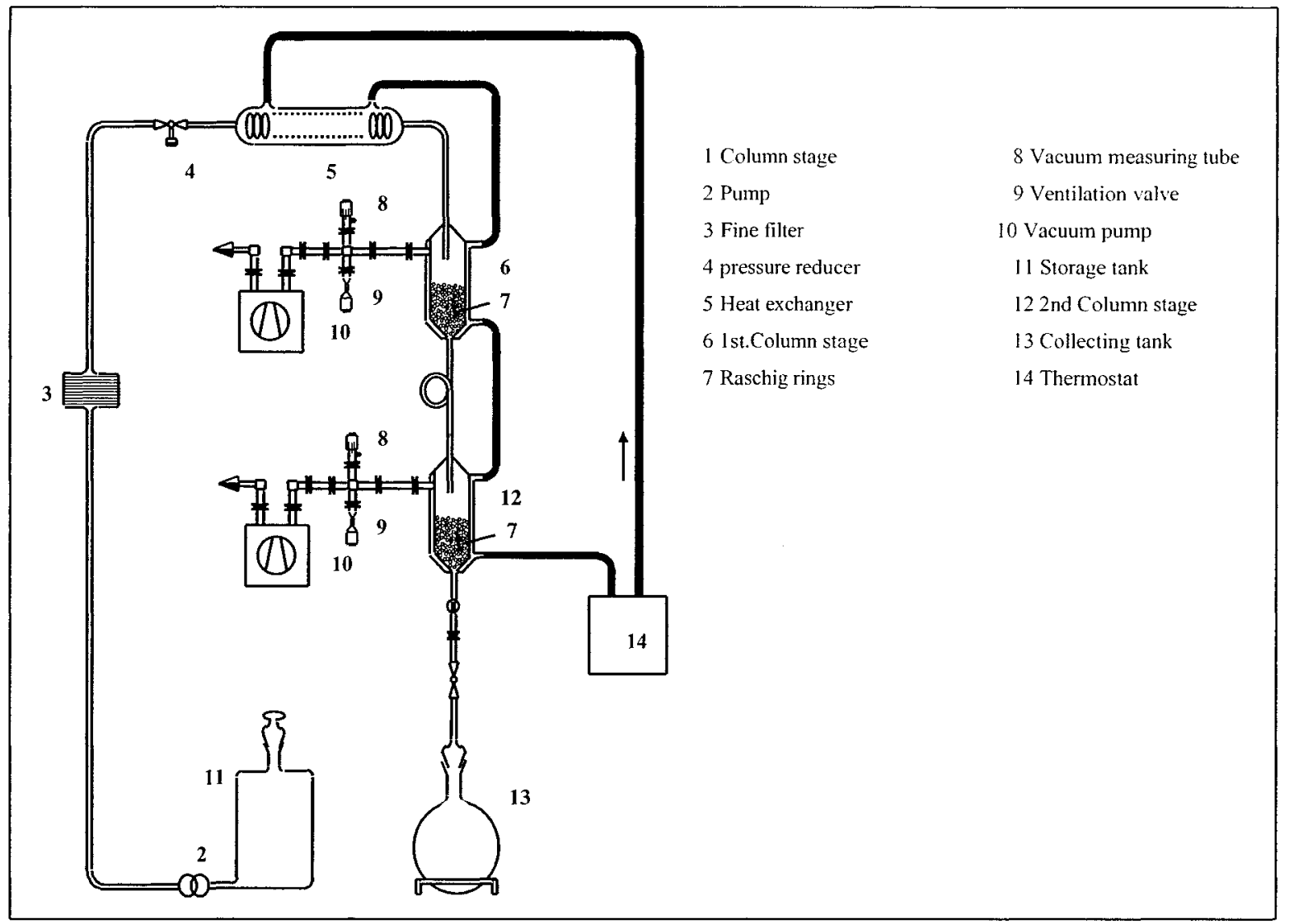

\subsubsection{Accelerated aging procedure}

The mechanism of ageing is a complex inter-disciplinary phenomenon. Insulating material ageing/degradation can be defined as an irreversible deleterious change to the serviceability of an insulation system. The primal process is that the chemical and physical bonds between the atoms of the insulation substance are repeatedly broken, reorganized and reformed into new configurations. Over time, the individual atomic processes collectively will give rise to microscopic and ultimately to macroscopic and recognizable change in the insulation substance and its ability to function.The ageing or deterioration of insulating oil is normally associated with oxidation under the very harsh environment. Electrical stress together with heat and moisture in the presence of a catalyst (e.g. oxygen from air) oxidises the oil producing free radicals, acids and sludge. Ageing is a gradual change of oil state and its properties that usually leads to a degree of breakdown. Because the general life is much 
longer than the research duration, the investigations were based on studying the aging effect with increased speed. The ageing procedure was done by placing oil specimens in a convection oven (Figure 1.2) at $100^{\circ} \mathrm{C}$ and aging them for an extended specific period, with/without air (oxygen) inlet. Typical transformer proportions of copper, aluminium, zinc and iron (each $3 \mathrm{~g} / 1$ ) was added to oil-paper insulation during the aging process in order to simulate the possible oxidation processes. The oil samples were aged at different aging times from 500 to 2000 hours which simulate long time service condition due to the used severe aging conditions. Fraction of the aged oil samples was reclaimed and/or degassed to assess the impact of aging by-products on the gassing. Thermal and electrical stresses will be submitted to the samples. DGA testing will be performed before and after stress applications.

The following standards were used to assess oil properties during this project.

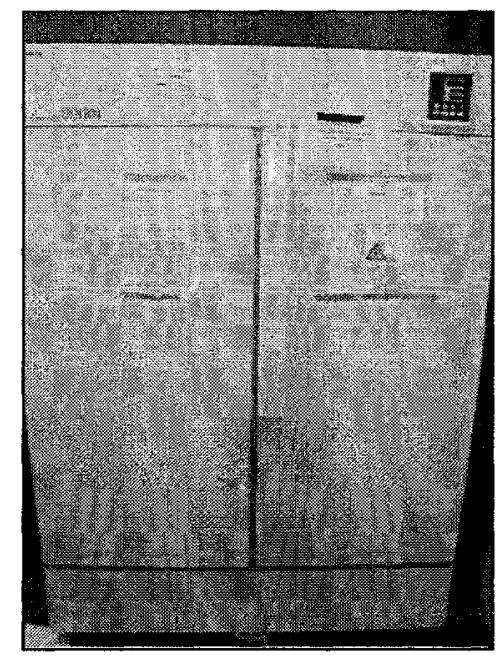

Figure 1.2. Mechanical Convection (Model DKN-900).

\subsubsection{Water Content (ASTM D 1533):}

The ASTM D 1533 [11] test method covers the measurement of water present in insulating liquids by coulometric Karl Fischer titration. One important parameter in oil moisture measurements is the water solubility. When the moisture in oil exceeds the solubility for that temperature, free water will form. The conventional way to measure water 
solubility is to make a saturated oil sample and then test the absolute moisture content. To achieve full saturation in transformer oil is difficult, especially at high temperature because of the high solubility [12].

Water can exist in transformer oil in three states [12]:

1. In practical cases, most water in oil is found in the dissolved state;

2. certain discrepancies in examining the moisture content using different measurement techniques suggests that water also exists in the oil tightly bound to oil molecules, especially in deteriorated oil;

3. When moisture in oil exceeds the saturation value, there will be free water precipitated from oil in suspension or drops.

By using Karl Fisher titration (Figure 1.3) based Coulometer, the water content in the oil in ppm, was determined. The measurements were repeated three times for each series of tests [12].

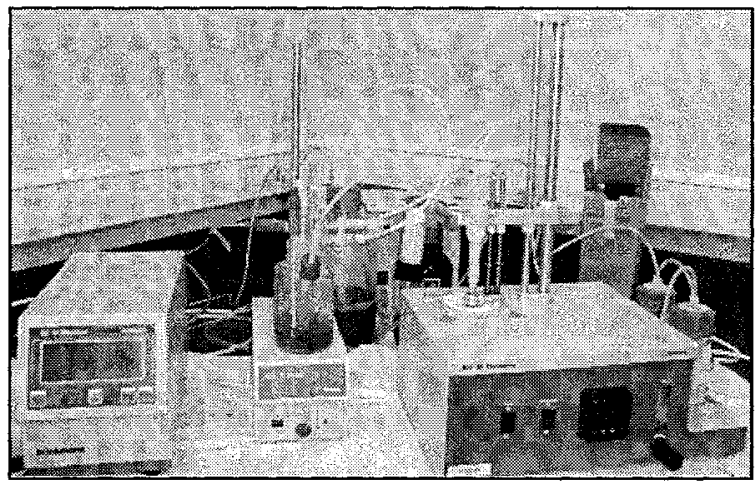

Figure 1.3. Karl Fischer (Model KF 831).

\subsubsection{Acidity (ASTM D 974):}

This test method (Figure 1.4) covers the determination of approximate Total Acid Number (TAN) of the oil sample. The result is provided in $\mathrm{mg}$ of $\mathrm{KOH} / \mathrm{g}$ [13]. This value is a measure of the amount of acidic materials present. The acidity and therefore the acid number increases as oil ages in service. Used oil having a high acid number indicates that the oil is either oxidized or contaminated with materials such as varnish, paint, or other foreign matter. 


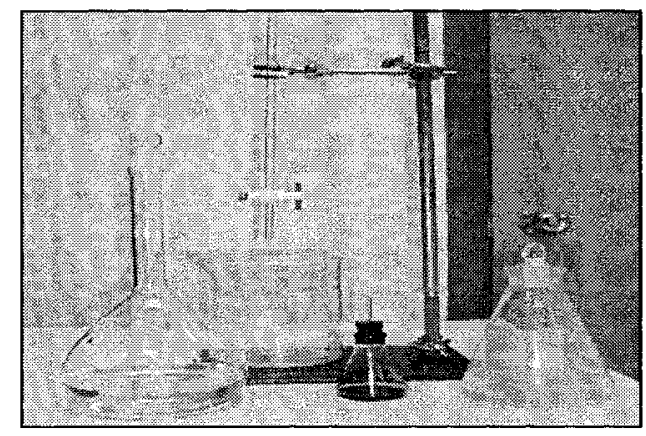

Figure 1.4. Setup for measuring the acidity of liquid.

\subsubsection{Interfacial Tension (ASTM D 971):}

The Interfacial Tension (IFT) of oil (Figure 1.5) is the force in dynes per centimetre required to rupture the oil film existing at an oil-water interface. When certain contaminants such as soaps, paints, varnishes, and oxidation products are present in the oil, the film strength of the oil is weakened, thus requiring less force to rupture. For aged oils, a decreasing value indicates the accumulation of contaminants, oxidation products, or both. It is a precursor of objectionable oxidation products which may attack the insulation and interfere with the cooling of transformer windings. Dividing the Interfacial Tension (IFT) by the Neutralisation Number (NN) provides a numerical value (Myers Index Number: MIN or oil quality index number: OQIN) provides a sensitive and reliable guide in determining the remaining useful life of a transformer oil [14].

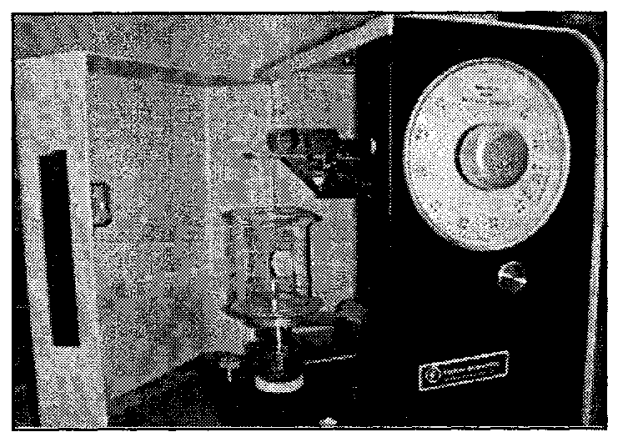

Figure 1.5. Tensiometer for measuring the interfacial tension of a liquid. 


\subsubsection{Turbidity (ASTM D 6181):}

This test method utilizes a ratio turbidimeter (Figure 1.6) to evaluate the degree of contamination by solid particles in suspension produced either from external sources such as varnish and metallic particles from the materials used in transformers or internal chemical reactions such as oxidation. The results are provided in NTU (Nephelometric Turbidity Units) [15].

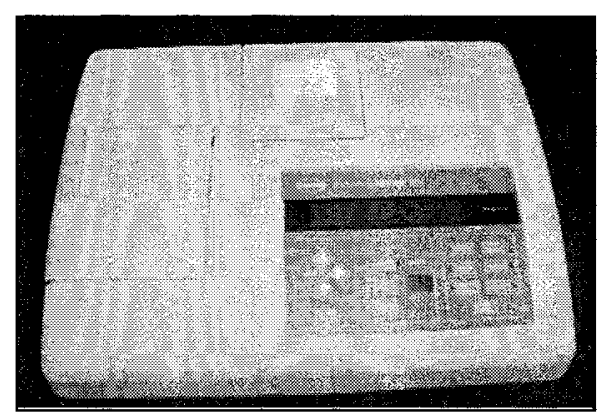

Figure 1.6. Turbidity meter for measuring cloudiness of liquid.

This method is an accurate optical laboratory technique developed to quantitatively determine the amount of microscopic solid suspension that may exist in both new and inservice fluids. Increasing turbidity signifies increasing fluid contamination. Other turbidity sources, such as water droplets or gas bubbles, are eliminated.

\subsubsection{Dissolved Decay Product (ASTM D 6802):}

This test method characterizes by spectrophotometer (Figure 1.7) the relative level of dissolved decay products in mineral insulating oils of petroleum origin [16].

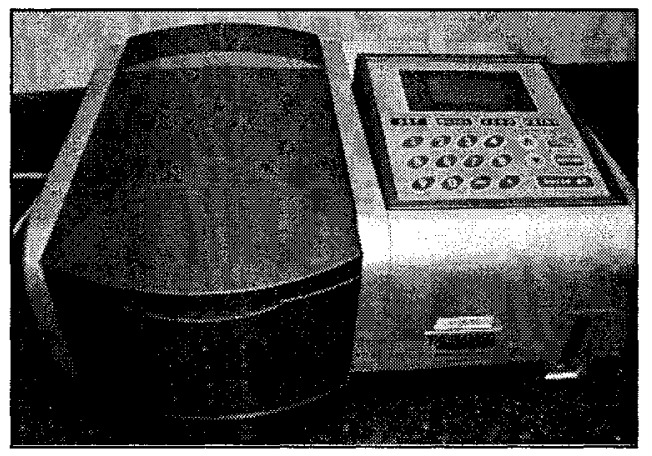

Figure 1.7. Spectrophotometer for measuring the relative dissolved decay products in oil.

This method is based upon the observation that in the range of visible spectrum all brands of new insulating liquids are almost completely transparent to a monochromatic beam of 
light. On the contrary, when the fluid contains decay products, the absorbance curve, as determined by a scanning spectrophotometer, significantly shifts to longer wavelengths. The numerical integration of the area below these absorbance curves permits the relative content of Dissolved oxidation Decay Products (DDP: peroxides, aldehydes, ketones and organic acids) in the fluid samples [16].

\subsubsection{Partial discharge:}

A partial discharge is a localized dielectric breakdown of a section of dielectrically stressed insulation path that occurs generally in voids, cracks, or interfaces within that insulating system or from the sharp edges of energized apparatus parts. These discharges may or may not exhibit a glow discharge, based on location and the intensity of these discharges [17]. The classic form of partial discharge is usually denoted by a visual glow or dielectric breakdown of the insulating air or gas around overstressed conductors or the sharp edges of energized apparatus parts [17].

In otder to simulate partial discharge in the fluid samples, a test cell designed in the ISOLIME laboratory (Figure 1.8) was used. It consists of a needle tip $(1.5 \pm 0.1 \mu \mathrm{m})$ to plane gap $(4 \mathrm{~cm})$. The partial discharge was initiated by the application of $30 \mathrm{kV}$ for an extended period of 1 hour.

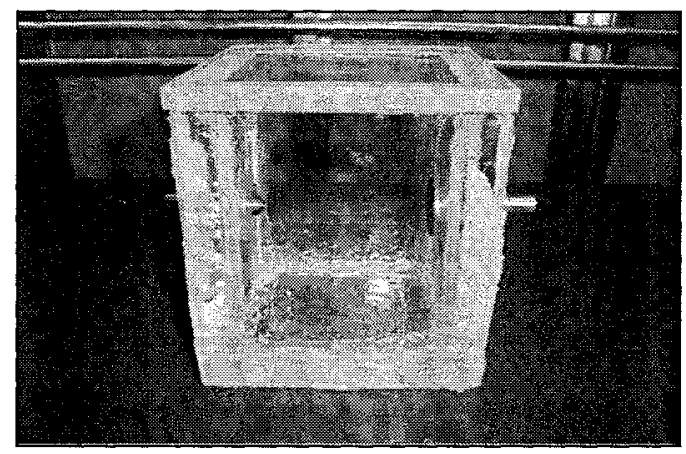

Figure 1.8. Test cell of partial discharge test.

\subsubsection{AC breakdown discharge (ASTM D 877):}

The dielectric breakdown voltage is a measure of the ability of an insulating liquid to withstand electrical stress. The power-frequency breakdown voltage of a liquid is 
reduced by the presence of contaminants such as cellulosic fibers, conducting particles, dirt, and water. Test Method D877 is not sensitive to low levels of these contaminants. Breakdown in this test method is dominated by events occurring at the electrode edges. The electrodes shall have parallel faces and axes in a coincident horizontal line when mounted in the cup. The spacing of the electrodes during tests was $2.54 \mathrm{~mm}(0.100$ inch $)$. The voltage stress distribution between the parallel disks electrodes used in this test method was quasi-uniform and there is substantial stress concentration at the sharp edges of the flat disk faces [18].

AC breakdown discharge was initiated in the oil sample to simulate incipient electrical breakdown. This was achieved using the liquid dielectric test set (Figure 1.9) [18]. The main purpose of that was an investigation of the effect of breakdown in transformer oils.

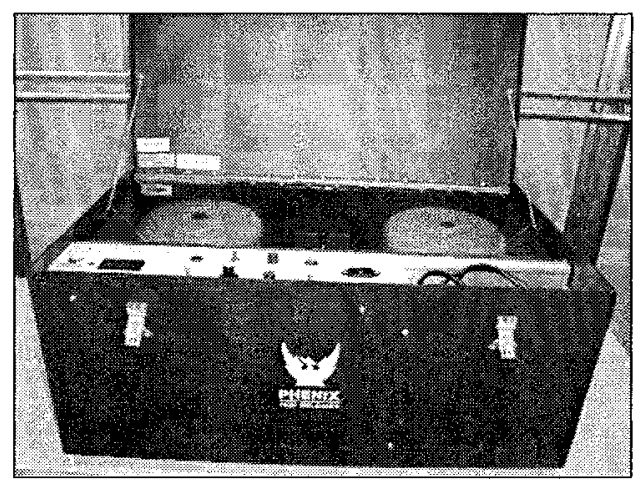

Figure 1.9. Model LD75 liquid dielectric test set.

\subsubsection{Dissolved Gas Analysis (ASTM D 3612A):}

In this test method dissolved gases are extracted from a sample of oil by gas chromatography (Figure 1.10).

By using dissolved gas analysis (DGA) it is possible to distinguish some faults such as partial discharge, breakdown and thermal fault because formation of these gases is dependent upon type of fault. There are several techniques in detecting those fault gases and DGA was recognized as the most informative method. This method involves sampling of the oil to measure the concentration of the dissolved gases.

Gas Chromatography is capable separating and detecting the gases of interest using a direct injection of a portion of the liquid samples. The apparatus must be capable of 
sufficiently separating the component gases, at the sensitivity levels, to ensure quantitative measurement of the respective peak areas [19].

DGA can detect fault gases generated by abnormal electrical and/or thermal operation in transformers. The main gases considered are $\mathrm{H}_{2}, \mathrm{CH}_{4}, \mathrm{C}_{2} \mathrm{H}_{2}, \mathrm{C}_{2} \mathrm{H}_{4}, \mathrm{C}_{2} \mathrm{H}_{6}, \mathrm{CO}$ and $\mathrm{CO}_{2}$. The relative quantities of these gases can be correlated with the fault type and the rate of gas generation can indicate the severity of the fault. In this work, for the analysis purpose the tested oils were sampled using $30 \mathrm{ml}$ syringe for DGA test.

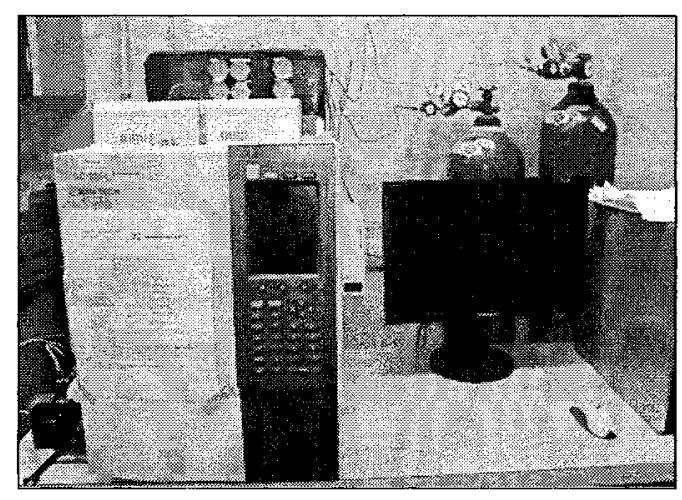

Figure 1.10. Gas chromatograph (GC).

\subsubsection{Stability test for mineral insulating Oils (ASTM D 6180-05)}

This test method covers a laboratory technique that measures the stability of new, used, or reclaimed insulating oils, similar to those described in the ASTM Specification D 3487 in the presence of controlled electric discharge. When subjected to electrical discharge, insulating oils absorb energy and produce gases as well as ionized molecules (charge carriers). The quantity of these decay products can be measured and can provide an indication of the stability of oils under the conditions of this test.

During this test, the insulating oil is subjected to high voltage discharge that generates free electrons. These electrons collide with the hydrocarbon molecules causing many of them to become electronically excited. Some of these molecules lose this energy as quanta of light emitting fluorescent radiation. Some of the other excited molecules decompose into gases, ionized molecules and free radicals. The measurement of these changes establishes the stability of oils under the conditions of this test method. The 
measures of these changes are the increase of the pressure in the test cells, the increase of dissipation factor and the turbidity of the oil specimen [10].

\subsection{Statement of the originality of the thesis}

In the last two decades, there has been considerable interest in the subject of life management of transformer equipment. To meet pressing needs of actual power industry new maintenance technologies, especially new diagnostic tools are necessary. In order to select a proper decision "What to do?" one ought to answer the question "What's the real condition of the equipment?" The easiest and the most accessible way to diagnose power transformer is to use transformer oil as efficient diagnostic media. The practice of the addition an oxidation stabilizer to transformer oil dates back almost 50 years. It was known that the elimination of oxygen as a source of contamination in a transformer significantly extended its life. Therefore, capability of oil transformer and oil-paper transformer to withstand decomposition under electrical discharge is more important for the safety of power transformers under operating conditions.

Currently, the electrical power industry believes that the gassing of oil is caused solely by hidden incipient electrical failures

Consequently, these are detected and diagnosed by periodic Dissolved Gas Analysis (DGA). DGA is probably the most widely used diagnostic tools for assessing the condition of electrical transformers and in more recent years load tap-changers and bulk oil circuit. As long as gases evolved by oil can randomly react before being determined by dissolved gas analysis (DGA), the attempt to diagnose the nature of incipient electrical failures based upon the chemical composition of gases is a "mission impossible". Consequently, the first step towards improving the accuracy of DGA should be the understanding of the impact of oxygen and aging byproducts on transformer oils gassing under the effect of electrical and thermal stresses. The investigations in this thesis aim at providing experimental evidence that oil born decay products contribute to the oil gassing. In addition, the formation in service conditions of undetected oil-born decay products is a contributing factor to the gassing of oil. The interpretation of DGA might be much more reproducible and relevant. Maintenance planners will therefore be in better position to take appropriate decisions. 


\subsection{Overview of the Thesis}

This thesis is presented in six chapters. After a general introduction in Chapter 1, a review of the methods used in literature for the most used interpretation techniques of dissolved gas analysis oil will be presented in Chapter 2. Since DGA play a central role in this research, Chapter 3 will provide some programmed interpretation techniques of DGA implemented in the Labview software, covering architectures used in the rest of the thesis. In Chapter 4, gassing stability and several characteristics of oil and complex oil-paper under electrical stress will be introduced. Chapter 5 begins with a preliminary analysis and a description of the impact of aging by products, electrical and thermal stresses applied to the oil samples on DGA techniques.

Finally, some general conclusions are summarized in Chapter 6, from analyses and discussions of the results reported in the previous chapters. In addition, some recommendations are provided for future research. 


\section{Chapter 2}

\section{Literature review}




\section{Chapter 2}

\section{Literature review}

\subsection{Introduction}

Transformer oil contains about $70 \%$ of diagnostic information [20]. The variations in different oil characteristics may therefore be used to identify/detect the type of incipient failure in the transformer. Diagnostic effectiveness by oil tests may be subdivided into four groups (Figure 2.1). Clearly, transformer failure may be avoided if the condition of the oil in an operational unit is monitored and, based on the results, corrective action is taken. Practically speaking, the lifetime of the transformer is directly related to the lifetime of the solid insulation. The evaluation of its deterioration is reliably performed by shaving at critical locations (leads, outer winding) and determining their tensile strength/degree of polymerization (DP). A non destructive alternative of this method is the measurement of furanic compounds released from the cellulose decomposition and dissolved in oil. Furfuraldehyde (2-FAL) has a strong correlation with the DP and criteria have been established to relate both properties [20] Another alternative recently proposed to access indirectly the DP is the Fast Fourier Transform Infrared (FTIR) offers promising avenues for an eventual implementation in the transformer body [20].

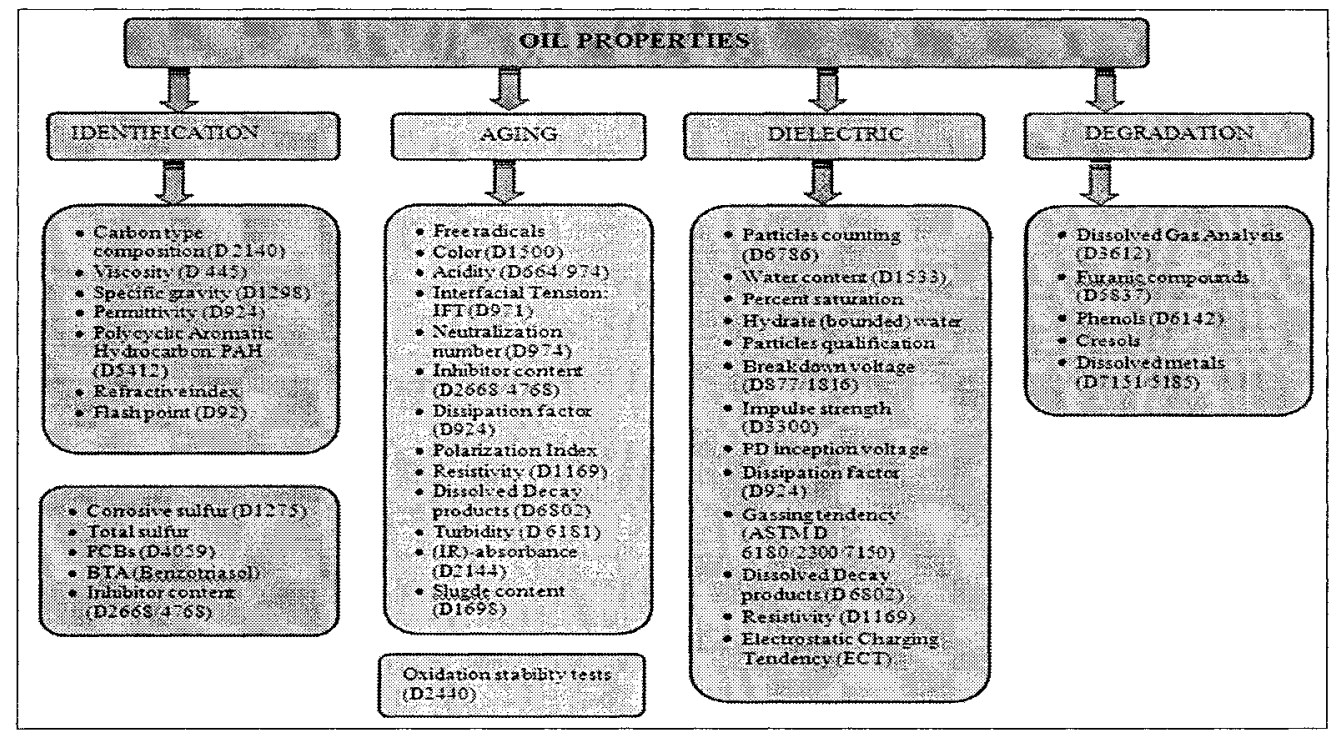

Figure 2.1. Functional based classification of oil properties [4]. 
Gases in oil always result from the decomposition of electrical insulation materials (oil or paper), as a result of faults or chemical reactions in the equipment. Such incipient electrical failures are one cause of certain hydrocarbons breakdown called "gassing" of oil. According to ASTM Designation D 3612-02 "Standard Test Method for Analysis of Gases Dissolved in Electrical Insulating Oil by Gas Chromatography", Section 1.2, indicates that the individual component gases that may be identified and determined include: Hydrogen$\mathrm{H}_{2}$, Oxygen- $\mathrm{O}_{2}$, Nitrogen- $\mathrm{N}_{2}$, Carbon Monoxide - $\mathrm{CO}$, Carbon Dioxide- $\mathrm{CO}_{2}$, Methane$\mathrm{CH}_{4}$ Ethane $-\mathrm{C}_{2} \mathrm{H}_{6}$, Ethylene $-\mathrm{C}_{2} \mathrm{H}_{4}$, Acetylene- $-\mathrm{C}_{2} \mathrm{H}_{2}$, Propane- $-\mathrm{C}_{3} \mathrm{H}_{8}$ and Propylene $-\mathrm{C}_{3} \mathrm{H}_{6}$. DGA is probably the most used tool for detecting faults in electrical equipment in service. About twenty DGA interpretation techniques have been developed so far. However, none of these methods are able to predict incipient failures in the transformer with accuracy close to or equal to $100 \%$.

\subsection{The Gassing of Oil}

Over the last decades, transformer capabilities have been improved by researchers due to competition among manufacturers. The voltages were increased in order to supply higher voltage transmission lines, and the power transformers were also physically sized down to minimize the cost. Contrary to this progress many laboratory techniques used to monitor the decay of oil insulation that are more than thirty years old and therefore are unable to detect the true cause of service reliability deterioration. The inability of outdated laboratory techniques to reveal the consequences of the oxidation decay process and especially the impact of the electrical stress put some researchers on a wrong track. Assessing the outcome of oxidation reactions solely by measuring the organic acidity and interfacial tension of oil (both more than thirty years old), the foreseeable formation of the colloidal sludge and $\mathrm{x}$-waxes was ignored. These unnoticed oil-born insoluble impurities clog the pores of paper insulation and generate hot spots. Instead, sophisticated techniques, supposedly capable of "diagnosing" the cause and nature of various incipient electrical failures based upon the "symptoms" of these deficiencies, have proliferated.

Gassing of oil is defined scientifically as the chemical decomposition of certain hydrocarbons, under the impact of various stresses. Since this process implies the decomposition of vulnerable hydrocarbons, the question arises as to the source of energy 
required for the splitting of a covalent bond. Basically, there are three sources of energy capable of transforming hydrocarbon molecules into decay products (Figure 2.2).

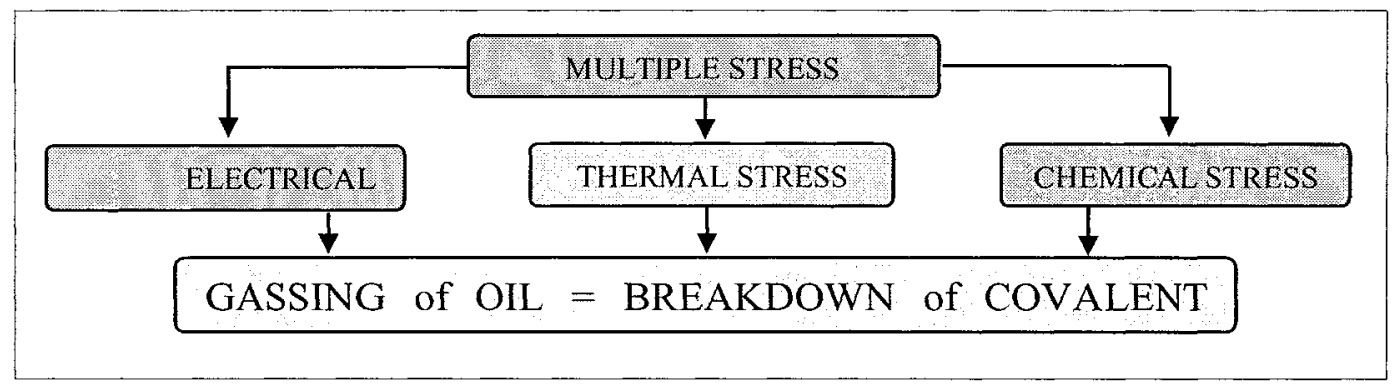

Figure 2.2. Potential causes of insulating liquid gassing.

Insulation oil used in power transformers consists of saturated hydrocarbons as paraffin and naphthene and as long as chemical bonds are not broken, the formations of decay products are delayed. Vulnerable molecules (R-R') decompose and generate a pair of free radicals $\left(R \bullet\right.$ and $\left.R^{\prime} \bullet\right)$. These fragments have an unpaired electron from a broken covalent bond and therefore are chemically very reactive.

$$
\mathrm{R}-\mathrm{R}^{\prime}+\mathrm{h} v \rightarrow \mathrm{R} \bullet+\mathrm{R} \cdot \bullet
$$

By secondary chemical reactions, the small fractions of the broken molecules generate usually a gas that dissolves in the oil without modifying the one phase system. Some of the hydrocarbon bonds may break and form free radicals: $\mathrm{H}^{*}, \mathrm{CH}_{3}{ }^{*}, \mathrm{CH}_{2}{ }^{*}$ and $\mathrm{CH}^{*}$.

All these radicals then recombine to form the fault gases observed in oil:

$$
\begin{aligned}
& \mathrm{H}^{*}+\mathrm{H}^{*} \rightarrow \mathrm{H}_{2} \text { (hydrogen) } \\
& \mathrm{H}^{*}+\mathrm{CH}_{3} * \rightarrow \mathrm{CH}_{4} \text { (methane) } \\
& \mathrm{CH}^{*}+\mathrm{CH}_{3}^{*} \rightarrow \mathrm{C}_{2} \mathrm{H}_{6} \text { (ethane) } \\
& \mathrm{CH}_{2}{ }^{*}+\mathrm{CH}_{2}{ }^{*} \rightarrow \mathrm{C}_{2} \mathrm{H}_{4} \text { (ethylene) } \\
& \mathrm{CH}^{*}+\mathrm{CH}^{*} \rightarrow \mathrm{C}_{2} \mathrm{H}_{2} \text { (acethylene) }
\end{aligned}
$$

In addition to these gases, the decomposition of paper produces $\mathrm{CO}_{2}, \mathrm{CO}$ and $\mathrm{H}_{2} \mathrm{O}$, because of the presence of oxygen atoms in the molecule of cellulose.

Since all low molecular weight fragments must have had an unpaired electron when the breakdown occurred, there is no doubt that the above mentioned gases (except $\mathrm{O}_{2}$ and $\mathrm{N}_{2}$ ) are in fact the result of secondary chemical reaction (Figure 2.3). 


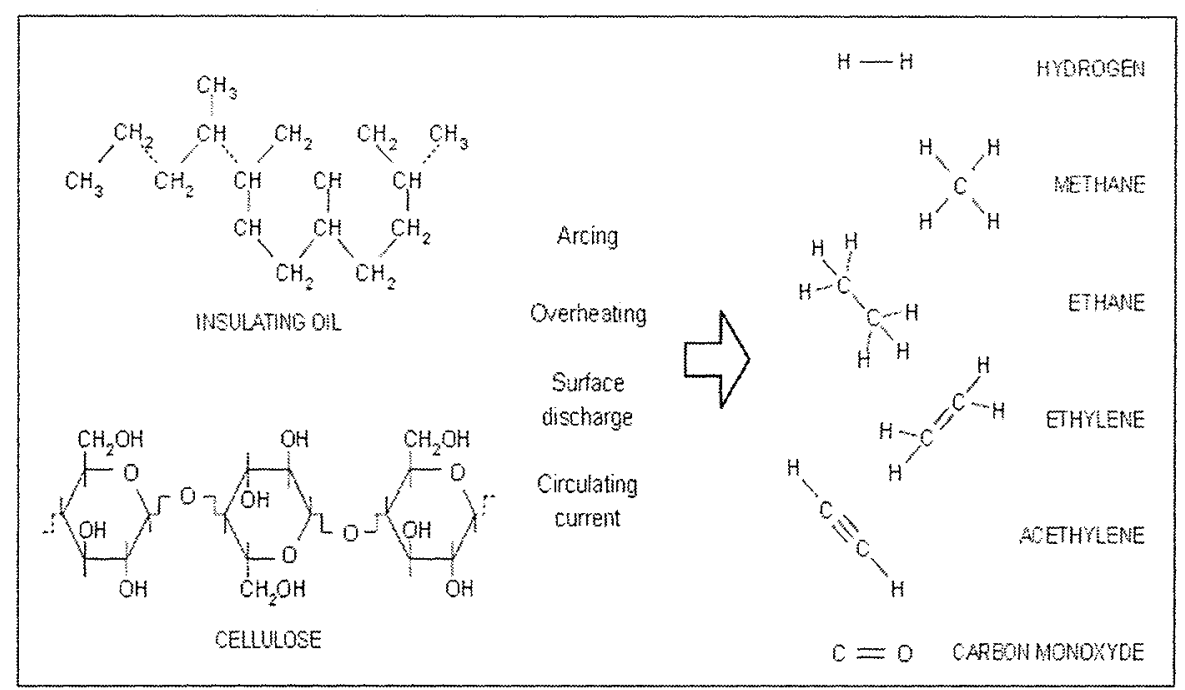

Figure 2.3. The decomposition of oil/paper caused by incipient failures [21].

As the population of free radicals increases, some gaseous or liquid fractions may capture a free electron and form an ion.

$$
\mathrm{R} \bullet+\mathrm{e}^{-} \rightarrow \mathrm{R}^{-}(2.2)
$$

The accumulation of such ionized molecules increases the dissipation factor of oilpaper insulation. When two large free radicals couple their unpaired electrons to generate a similar insoluble hydrocarbon without oxygen in the middle, the decay product formed has the generic name of $x$-wax. The increase in free radicals population increases random chemical reactions between free radicals and soluble and insoluble oilborn decay products are the result (Figure 2.4) [22].

The terminal stage of the liquid deterioration process is sludge or $\mathrm{x}$-waxes and acid in sufficient quantity to impair its heat transfer and dielectric properties [22]. 


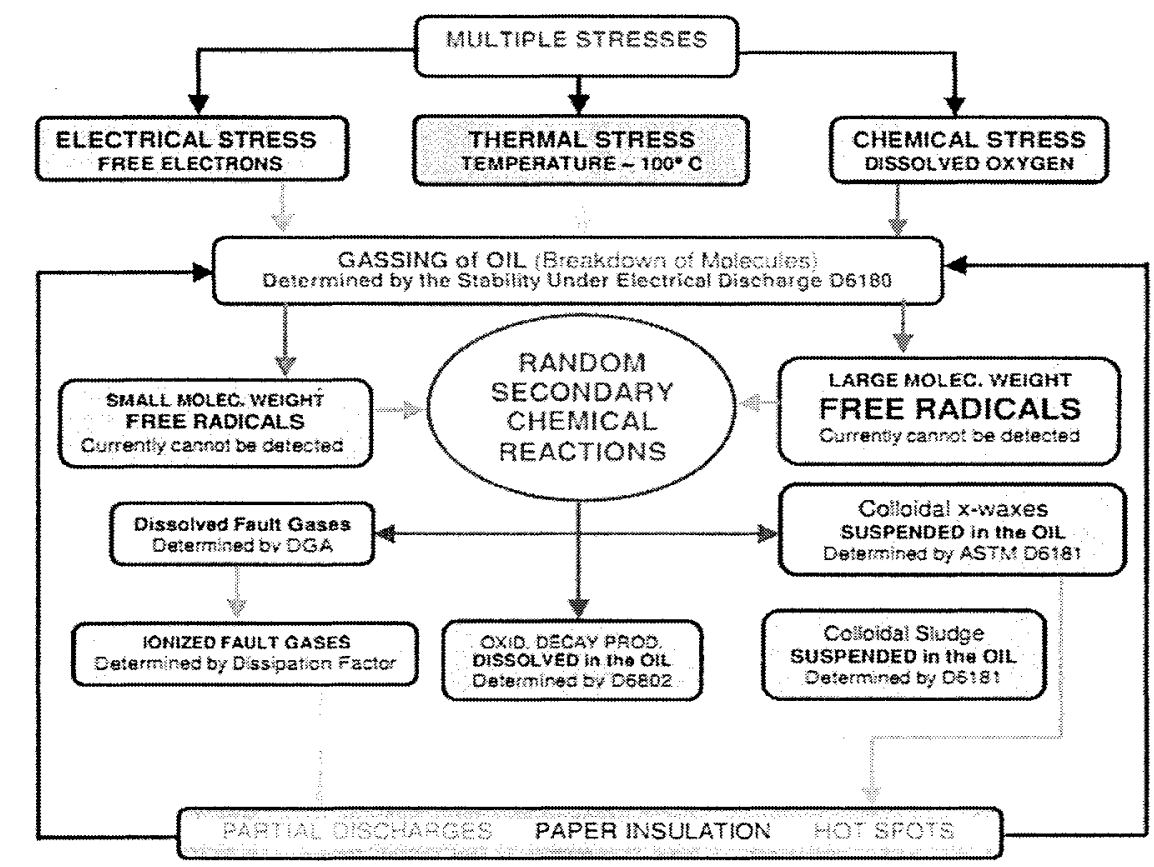

Figure 2.4. Sketch of insulating oil decaying processes, inside a free breathing power transformer [22].

While general agreement exists that the increase of dissolved gases concentration represents an early warning that a local deterioration of insulation occurred, there are different opinions regarding the interpretation of this concerning symptom. The lack of consensus is even more evident when attempts are made to pinpoint the cause of the phenomenon, based upon the chemical composition of dissolved gases. A summary of the empirical methods suggested since the beginning of the dissolved gases analysis are exposed [7]:

- Incipient Fault Types, Frank M. Clark, 1933/1962

- Dörnenburg Ratios, E. Dörnenburg, 1967, 1970

- $\quad$ Potthoff's Scheme, K. Potthoff, 1969

- Absolute limits, various sources, introduced in the 70s

- $\quad$ Shank's Visual Curve method, 1970s

- Trilinear Plot Method, introduced in the 70s

- $\quad$ Key Gas Method, David Pugh, 1974

- $\quad$ Duval's Triangle, Michel Duval, 1974

- $\quad$ Rogers Ratios, R. R. Rogers, 1975 
- $\quad$ Glass Criterion, R. M Glass, 1977

- Trend Analysis, various sources, introduced in the $80 \mathrm{~s}$

- Total volume per day ppm per day

- Church Logarithmic Nomograph, J. O. Church, 1980

- $\quad$ Expert System Analysis, Richard Lowe, 1985

- $\quad$ Expert System Monitor Program, Karen Barrett, 1989

- Transformer Fingerprinting

- IEEE C57.104, Limits, rates and TDCG, 1978/1991

- $\quad$ Artificial Neural Networks (ANNs) and Fuzzy Logic

- $\quad$ X. Ding, E. Yao, Y. Liu and Paul Griffin, 1996

- Vladimiro Miranda and Adriana Garcez Castro, 2004

- $\quad$ Donald Lamontagne, 2006

- $\quad$ IEC 60599 Ratios, Limits and gassing rates, 1999

- Data mining and Log Transformation, Tony McGrail, 2000

- Vector Algorithm, Nick Dominelli, Mike Lau and David Pugh, 2004.

Among the available DGA techniques, the most used are IEC, Roger's, Duval's Triangle and the Key Gas methods [23, 24, 25, and 26]. The advantages to any ratio method are that they are quantitative and independent of transformer oil volume. However, ratio methods can produce incorrect interpretations or none at all. Therefore they should be used in conjunction with other diagnostic methods such as the Key Gas method. Additionally minimum levels of gases must be present before results of the ratio methods become significant. One drawback of the gas ratio methods (Dörnenburg, Rogers, IEC) is that some DGA results may fall outside the ratio codes and no diagnosis can be given (unresolved diagnoses). This does not occur with the Triangle method because it is a closed system rather than an open one.

\subsubsection{DGA most used Interpretation Techniques}

There are several methods for analyzing the dissolved gas results, most commonly used methods are listed below: 


$\begin{array}{ll}* & \text { Duval Triangle } \\ * & \text { IEEE C57.104, Limits, rates and TDCG } \\ * & \text { Straight Limits } \\ * \quad \text { Dey Gas Method } \\ * \quad \text { Rogers Ratios } \\ * \quad \text { TEC 60599 Ratios and Limits } \\ * \quad \text { Trend Analysis } \\ \text { * } \quad \text { Expert System Analysis }\end{array}$

Duval's method appears to be more accurate than other methods according to Table 2.1. One advantage of this method is that, it always provides a diagnosis, with a low percentage of wrong diagnoses. Duval's method was developed empirically in the early 1970s [27].

Table 2.1. Comparison of some diagnosis methods [7].

\begin{tabular}{|l|l|l|l|}
\hline & $\begin{array}{l}\% \text { Unresolved } \\
\text { diagnoses }\end{array}$ & $\begin{array}{l}\% \text { Wrong } \\
\text { diagnoses }\end{array}$ & $\%$ Total \\
\hline Key gases & 0 & 58 & 58 \\
\hline Rogers & 33 & 5 & 38 \\
\hline Dornenburg & 26 & 3 & 29 \\
\hline IEC & 15 & 8 & 23 \\
\hline Triangle & 0 & 4 & 4 \\
\hline
\end{tabular}

\subsubsection{Traditional DGA methods}

The three traditional DGA methods implemented in this study are (i) Roger's Ratio Method (RRM), (ii) Dörnenburg's Ratio Method (DRM) and (iii) the Duval's triangle method. These methods have been programmed in the Labview software due to their high accuracy and similar structure.

The fingerprint gases used by all the three methods to be harnessed are Carbon Monoxide $(\mathrm{CO})$, Hydrogen $\left(\mathrm{H}_{2}\right)$, Methane $\left(\mathrm{CH}_{4}\right)$, Ethane $\left(\mathrm{C}_{2} \mathrm{H}_{6}\right)$, Ethylene $\left(\mathrm{C}_{2} \mathrm{H}_{4}\right)$ and 
Acetylene $\left(\mathrm{C}_{2} \mathrm{H}_{2}\right)$. Conventionally, all the above DGA techniques make decisions based on the values of the ratios they use.

\subsection{Summary}

Power systems and transformer are essential apparatus, hence its reliability and safe operation is important to determine their operation conditions, and the industry uses quality control tests in the insulation design of oil filled transformers.

The gas generation process in an insulating liquid involves the decomposition of certain vulnerable molecules. Generally, there are three energy sources that can break up large molecules of vulnerable covalent bonds to form gases and decay products: the electric field, thermal energy generated by the active part of the transformer and environmental stresses.

The unavoidable presence of dissolved oxygen in the insulating liquids contributes to the degradation of this later. Oil-born decay products generated by oxygen degrade the internal winding insulation, decrease service reliability, and shorten the life expectancy of electrical transformers.

Accurate methods of estimating the gassing tendency of liquids have been proposed and standardized. Special attention has been paid to gas formation under partial discharge (PD), which is inevitably present in power equipment, even under normal operating conditions. 


\section{Chapter 3}

\section{Implementation of some methods in Labview}




\section{Chapter 3}

\section{Implementation of some methods in Labview}

\subsection{Introduction}

The actual operating condition of transformers in power grid is an important aspect viewing the stability of the power supply. Economic pressure forces power utilities to introduce efficient maintenance strategies carrying out only the most important jobs. In order to conserve transformers "health", appropriate maintenance and diagnostic tools are necessary-

In power transformer monitoring and diagnostic applications, maintenance engineers, face the complexity and diversity of tasks associated with this complex domain. This often arises from dealing with different types of information from different sources, which require processing with different diagnostic schemes. This problem may neither fit the assumptions of a single technique nor be effectively solved by the strengths and capabilities of a single technique. Combined diagnostic techniques can be very useful for experts to detect transformer faults and reduce the risk of mistaken diagnostics. Merging various techniques should be a significant move forward in the next generation of diagnostic and monitoring systems. In this contribution, a Labview-based expert system has been implemented. By combining DGA diagnostic methods, the risk of mistaken diagnostics might be reduced and the likelihood maximized to identify faults before they lead to transformer failures.

\subsection{Realized work in Labview}

A user friendly program has been developed to analyze the dissolved gas results extracted from an oil sample by GC. The front panel of the system (Figure 3.1) was designed using Labview to enable computer to act as customer-designed instrument. The dissolved gas-in-oil analysis (DGA) method was used as technique for oil type transformer diagnosis. The block diagram depicted in Figure 3.2 was used as expert system to implement all information keyed in at the front panel to diagnose and predict the condition of the transformer. The outcome of the interpretation is displayed in the front panel of Labview, to show the user, the conditions of the transformer at any time. 


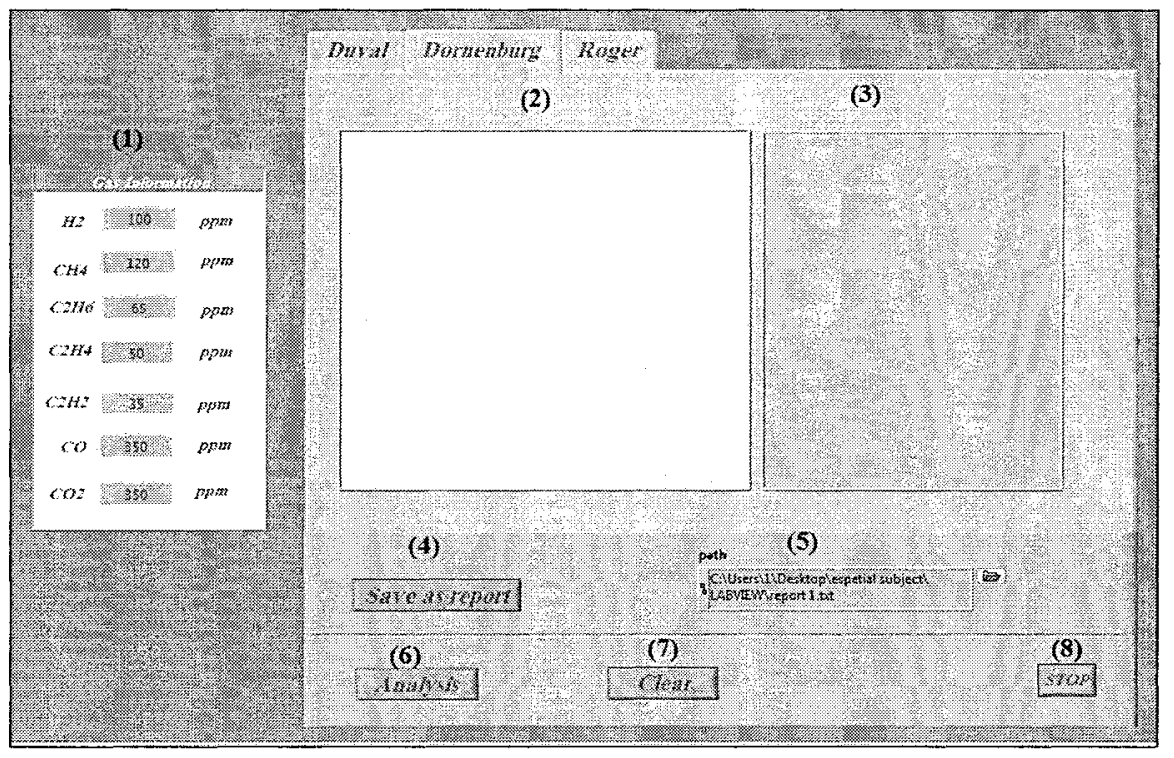

Figure 3.1. Overview of the main interface of the Labview program.

As shown in the Figure 3.1, the main program consists in the following sections:

(1) Input data

(2) Choice of analyzing method (Duval, Dörnenburg, Roger)

(3) On line report and results menu

(4) Saving the report as a text file

(5) Path to save the report as

(6) Analysis button to start analyzing

(7) Clear the on line results

(8) Program stopping button 


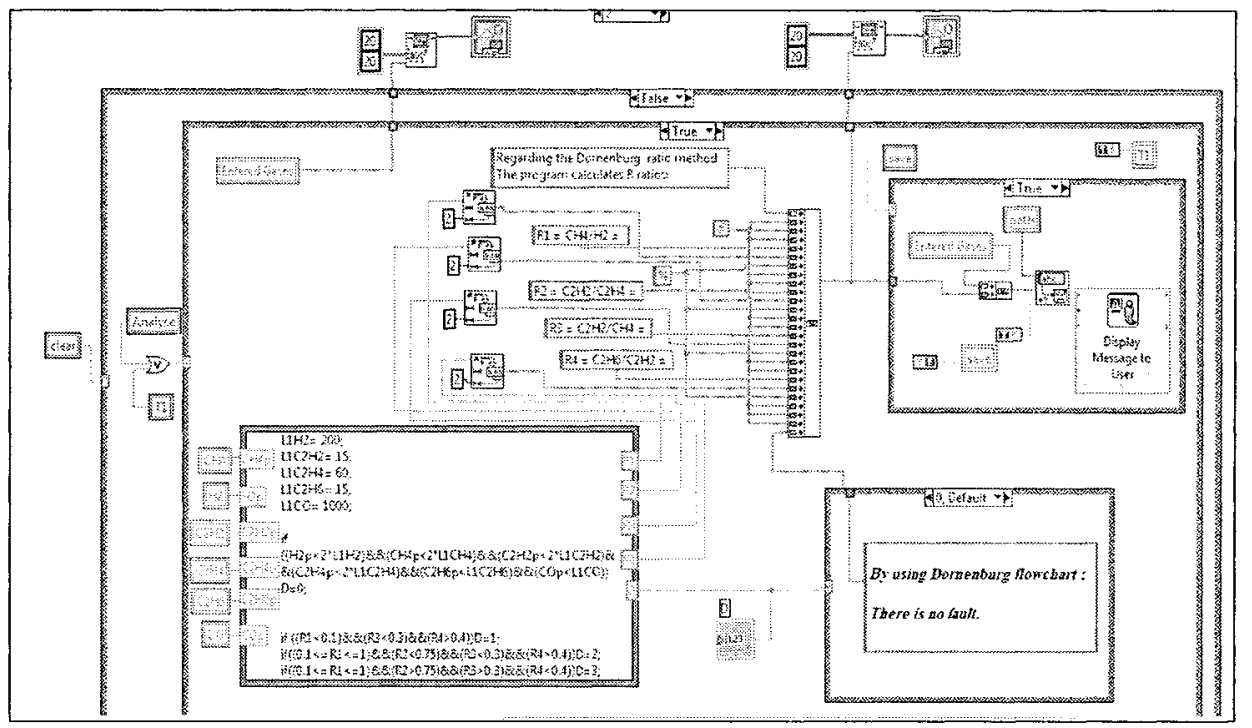

Figure 3.2. Block diagram of the program.

The program was developed for three methods, Roger, Dörnenburg and Duval. The following section explains the application of the program for these methods.

\subsubsection{Roger's Ratio Method}

Roger's Ratio Method is presented in Table 3.1, and the ratios employed for diagnosis are derived from various combinations of the fingerprint gases (Mollmann et al. 1999) [28].

Table 3.1. Roger's Ratio Method

\begin{tabular}{|c|c|c|c|c|}
\hline Case & $\begin{array}{c}\mathrm{R2} \\
\mathrm{C}_{2} \mathrm{H}_{2} / \mathrm{C}_{2} \mathrm{H}_{4}\end{array}$ & $\begin{array}{c}\mathrm{R} 1 \\
\mathrm{CH}_{4} / \mathrm{H}_{2}\end{array}$ & $\begin{array}{c}\mathrm{R} 5 \\
\mathrm{C}_{2} \mathrm{H}_{4} / \mathrm{C}_{2} \mathrm{H}_{6}\end{array}$ & Fault \\
\hline 0 & $<0.1$ & $>0.1,<1.0$ & $<1.0$ & Normal \\
\hline 1 & $<0.1$ & $<0.1$ & $<1.0$ & $\begin{array}{c}\text { Low energy } \\
\text { PD }\end{array}$ \\
\hline 2 & $0.1-3.0$ & $0.1-1.0$ & $>3.0$ & $\begin{array}{c}\text { Arcing } \\
\text { (n) }\end{array}$ \\
\hline 3 & $<0.1$ & $>0.1<1.0$ & $1.0-3.0$ & $\begin{array}{c}\text { Low temp } \\
\text { thermal }\end{array}$ \\
\hline 4 & $<0.1$ & $>1.0$ & $1.0-3.0$ & $\begin{array}{c}\text { Thermal } \\
<700^{\circ} \mathrm{C}\end{array}$ \\
\hline 5 & $<0.1$ & $>1.0$ & $>3.0$ & $\begin{array}{c}\text { Thermal } \\
>700^{\circ} \mathrm{C}\end{array}$ \\
\hline
\end{tabular}

There are three ratios in Roger's method:

$$
\text { - Ratio } 1\left(\mathrm{R}_{1}\right)=\mathrm{CH}_{4} / \mathrm{H}_{2}
$$




$$
\begin{aligned}
& -\quad \text { Ratio } 2\left(\mathrm{R}_{2}\right)=\mathrm{C}_{2} \mathrm{H}_{2} / \mathrm{C}_{2} \mathrm{H}_{4} \\
& -\quad \text { Ratio } 5\left(\mathrm{R}_{5}\right)=\mathrm{C}_{2} \mathrm{H}_{4} / \mathrm{C}_{2} \mathrm{H}_{6}
\end{aligned}
$$

Figure 3.3 shows the application of this program for Roger's method.

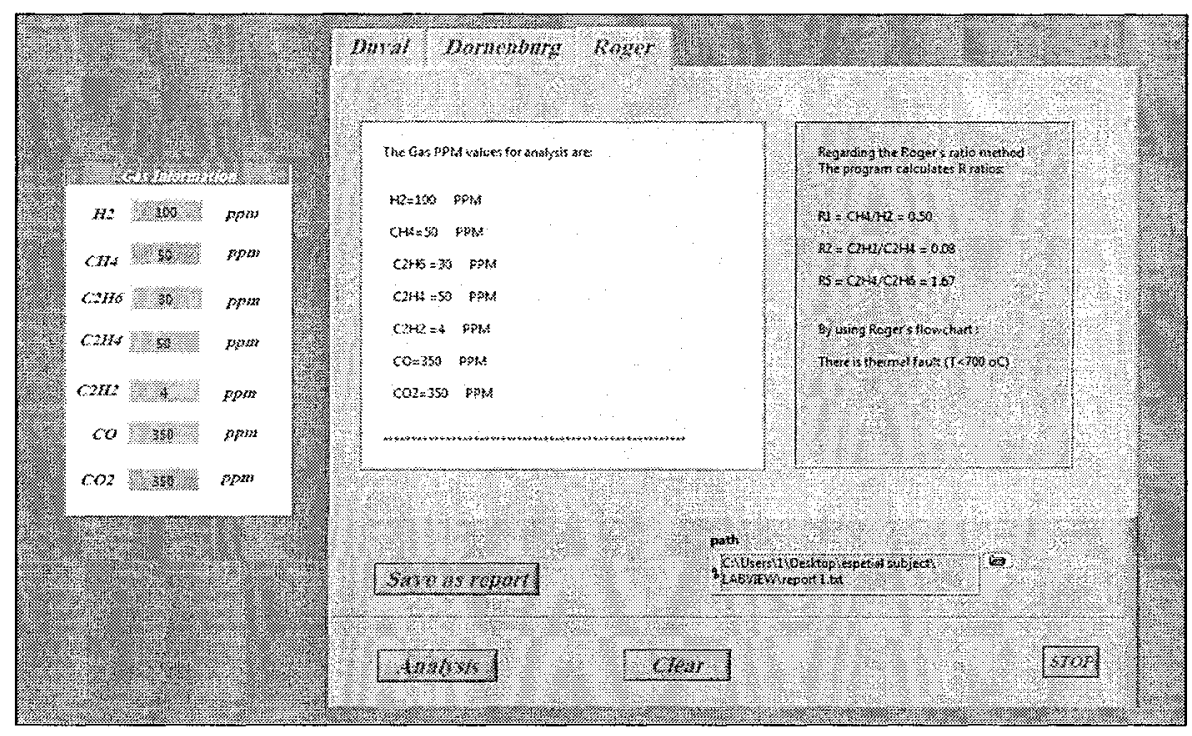

Figure 3.3. Implementation of Roger's method in Labview.

As an example shown in Figure 3.3, the values of gases as inputs for this method are:

$\mathrm{H}_{2}=100 \mathrm{ppm}, \mathrm{CH}_{4}=50 \mathrm{ppm}, \mathrm{C}_{2} \mathrm{H}_{6}=30 \mathrm{ppm}, \mathrm{C}_{2} \mathrm{H}_{4}=50 \mathrm{ppm}, \mathrm{C}_{2} \mathrm{H}_{2}=4 \mathrm{ppm}$

After analyzing the method, the ratios were calculated and the program also provides a short report indicating a thermal fault as shown in Figure 3.4.

\section{By using Roger's flowchart:}

There is thermal fault $(T<700$ oC)

Figure 3.4. Example of Roger's fault.

\subsubsection{Dörnenburg's Ratio Method}

For Dörnenburg's Ratio Method, the fingerprint gas ratios are compared with some predetermined values to determine the types and levels of faults. The relationships between fault types and the applied ratios are listed in Tables 3.2 and Table 3.3 [28]. 
Table 3.2. Dörnenburg's Ratio Method.

\begin{tabular}{|l|c|c|c|c|}
\hline Fault & $\mathrm{R}_{1}$ & $\mathrm{R}_{2}$ & $\mathrm{R}_{3}$ & $\mathrm{R}_{4}$ \\
\hline Thermal & $>1.0$ & $<0.75$ & $<0.3$ & $>0.4$ \\
\hline $\mathrm{PD}$ & $<0.1$ & $\mathrm{~N} / \mathrm{A}$ & $<0.3$ & $>0.4$ \\
\hline Arcing & $>0.1 \&<1.0$ & $>0.75$ & $>0.3$ & $<0.4$ \\
\hline
\end{tabular}

Table 3.3. Dörnenburg's L1 Limits.

\begin{tabular}{|l|c|c|c|c|c|c|}
\hline Gas & $\mathrm{H}_{2}$ & $\mathrm{CH}_{4}$ & $\mathrm{CO}$ & $\mathrm{C}_{2} \mathrm{H}_{2}$ & $\mathrm{C}_{2} \mathrm{H}_{4}$ & $\mathrm{C}_{2} \mathrm{H}_{6}$ \\
\hline $\mathrm{Ll}(\mathrm{ppm})$ & 100 & 120 & 350 & 35 & 50 & 65 \\
\hline
\end{tabular}

There are four ratios in Dörnenburg's method:

- Ratio $1\left(\mathrm{R}_{1}\right)=\mathrm{CH}_{4} / \mathrm{H}_{2}$

Ratio $2\left(\mathrm{R}_{2}\right)=\mathrm{C}_{2} \mathrm{H}_{2} / \mathrm{C}_{2} \mathrm{H}_{4}$

- Ratio $3\left(\mathrm{R}_{3}\right)=\mathrm{C}_{2} \mathrm{H}_{2} / \mathrm{CH}_{4}$

- Ratio $4\left(\mathrm{R}_{4}\right)=\mathrm{C}_{2} \mathrm{H}_{6} / \mathrm{C}_{2} \mathrm{H}_{2}$

Figure 3.5 shows the application of this program for Dörnenburg's method.

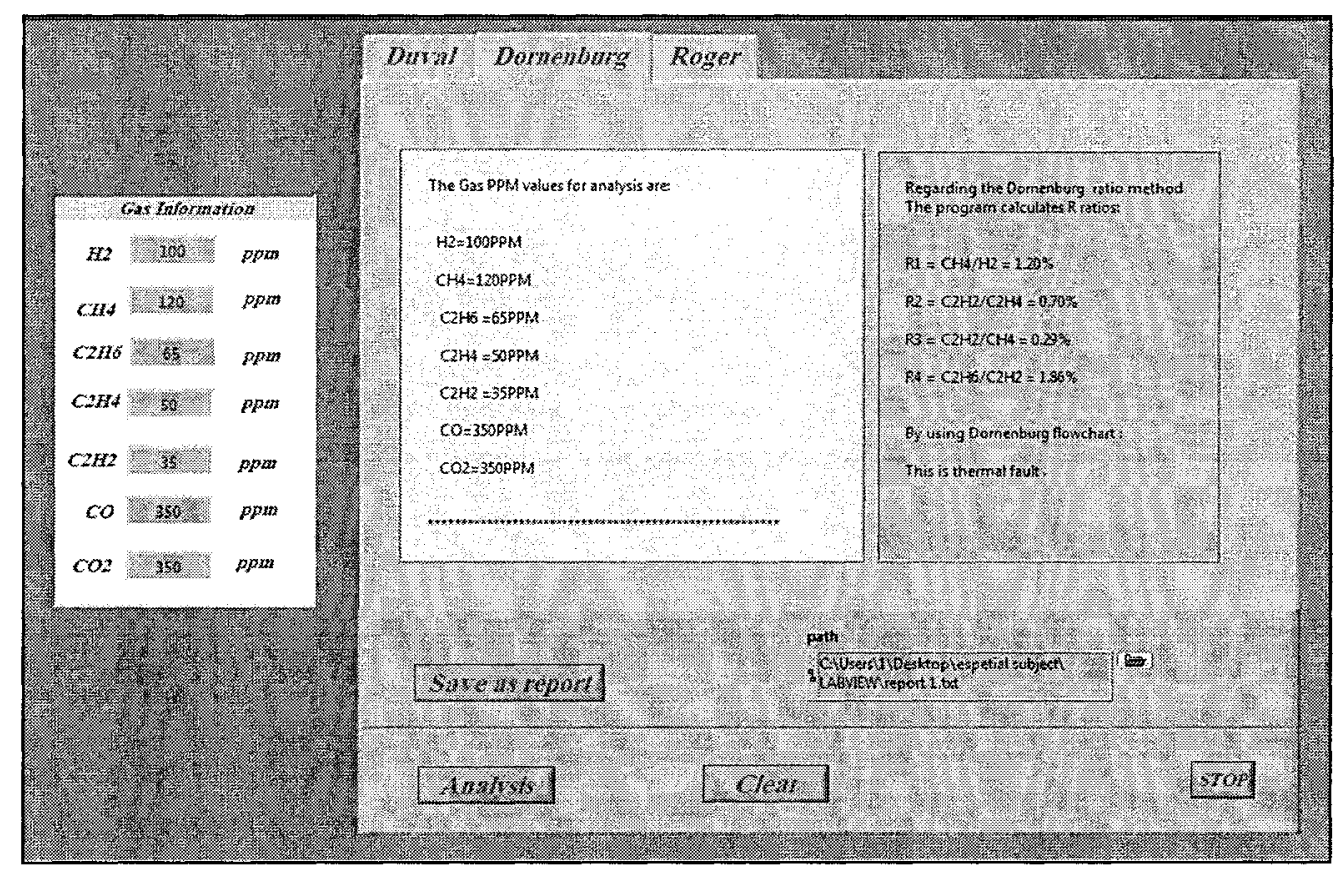

Figure 3.5. Dörnenburg's ratio method in Labview. 
As an example shown in Figure 3.5, the values of gases, as inputs for this method are:

$\mathrm{H}_{2}=100 \mathrm{ppm}, \mathrm{CH}_{4}=120 \mathrm{ppm}, \mathrm{C}_{2} \mathrm{H}_{6}=65 \mathrm{ppm}, \mathrm{C}_{2} \mathrm{H}_{4}=50 \mathrm{ppm}, \mathrm{C}_{2} \mathrm{H}_{2}=35$ ppm. After analyzing the method, the program gives a short report that, there is arcing fault according to Figure 3.6 .

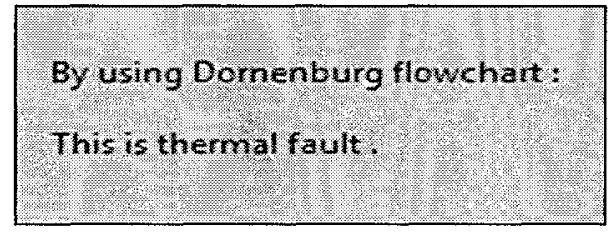

Figure 3.6. Example of Dörnenburg's fault.

\subsubsection{Duval Triangle Method}

The Duval's Triangle diagnostic method for oil-insulated high-voltage equipment (mainly transformers) was developed by Michel Duval [6]. The triangle representations allow following easily, graphically and visually the evolution of faults with time objectives. However many people are not quite familiar with the use of triangular coordinates.

Several software packages are available for DGA interpretation using the Duval triangle method. Concentrations (ppm) of methane $\left(\mathrm{CH}_{4}\right)$, ethylene $\left(\mathrm{C}_{2} \mathrm{H}_{4}\right)$, and acetylene $\left(\mathrm{C}_{2} \mathrm{H}_{2}\right)$ are expressed as percentages of the total $\left(\mathrm{CH}_{4}+\mathrm{C}_{2} \mathrm{H}_{4}+\mathrm{C}_{2} \mathrm{H}_{2}\right)$ and plotted as a point $\left(\% \mathrm{CH}_{4}, \% \mathrm{C}_{2} \mathrm{H}_{4}, \% \mathrm{C}_{2} \mathrm{H}_{2}\right)$ in a triangular coordinate system on a triangular chart which has been subdivided into fault zones. The fault zone in which the point is located designates the likely fault type which produced that combination of gas concentrations [27].

The six main zones of faults are indicated in the triangle, plus a DT zone (mixture of thermal and electrical faults). These zones are summarized as below:

PD: Partial discharge

T1: Low-range thermal fault (below $300^{\circ} \mathrm{C}$ )

T2: Medium-range thermal fault $\left(300-700^{\circ} \mathrm{C}\right)$

T3: High-range thermal fault (above $700^{\circ} \mathrm{C}$ ) 

D1: Low-energy electrical discharge
D2: High-energy electrical discharge
DT: Indeterminate - thermal fault or electrical discharge.

Figure 3.7 shows the application of this program for Duval's method.

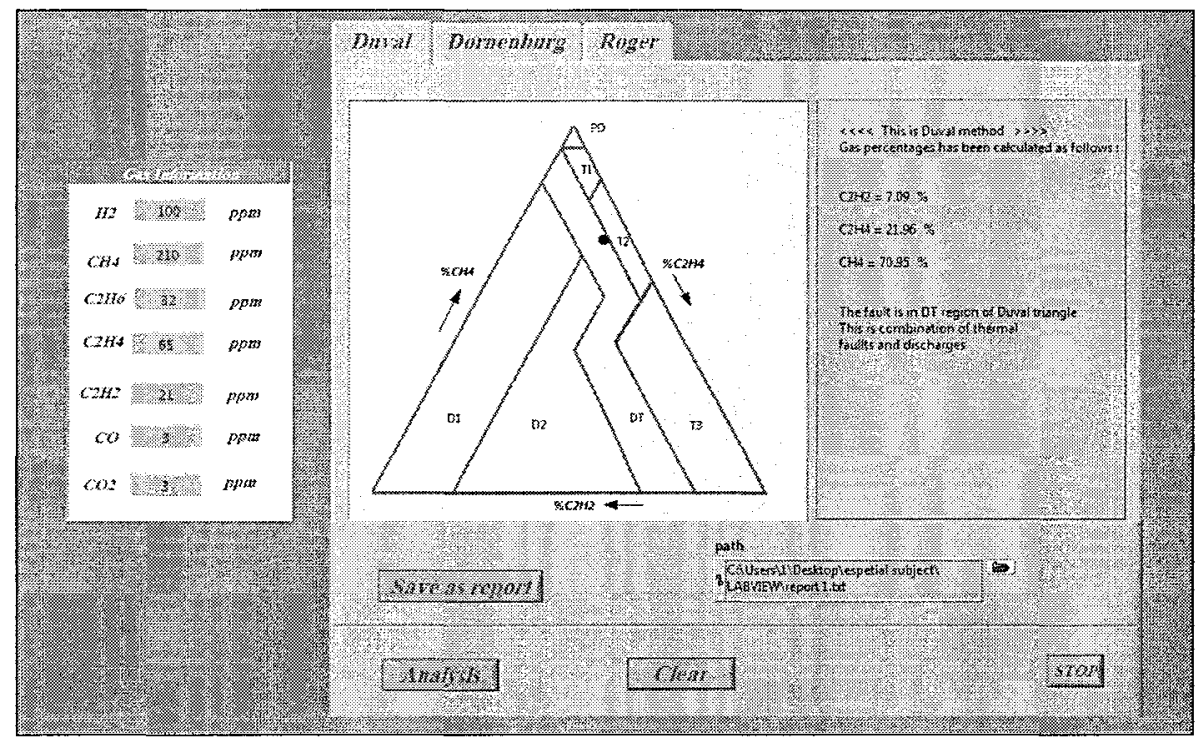

Figure 3.7. Duval's Triangle in Labview.

As an example shown in the above figure, the values of gases as inputs for this method are: $\mathrm{CH}_{4}=210 \mathrm{ppm}, \mathrm{C}_{2} \mathrm{H}_{4}=65 \mathrm{ppm}, \mathrm{C}_{2} \mathrm{H}_{2}=21 \mathrm{ppm}$.

After analyzing the method, the ratios have been calculated and the program gives a short report that, there is combination of thermal and discharge fault according to Figure 3.8 .

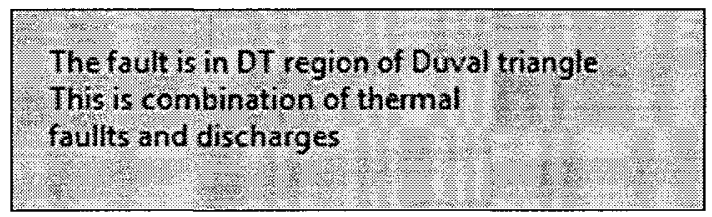

Figure 3.8. Example of Duval's fault. 


\subsection{Summary}

Condition monitoring of electrical power equipment has attracted considerable attention for many years. The aim of this chapter is to use Labview to build a simulation system to diagnose transformer faults and monitor its condition.

Dissolved gas analysis (DGA) is one of the most useful techniques to detect incipient faults in oil-filled power transformers. Various methods have been developed to interpret DGA results such as ratios methods (Rogers', Dörnenburg, IEC) and Duval's method. One weak point in ratio methods is that they fail to cover all ranges of data and sometimes ratios fall outside the scope of tables. All together, there is always some degree of inaccuracy in dissolved-gas measurements. This inaccuracy affects gas ratios and other diagnostic calculations. Therefore, the results based on them may be correspondingly uncertain in some cases and they sometimes fail to determine the faults. There is no single DGA technique that alone can guarantee to detect all the range of faults and give a reliable estimation of transformer condition. For this reason combination of DGA diagnostic techniques are required to enhance reliability of diagnosis. In this chapter, Labview-based software was developed. This software includes three of the most commonly used techniques, namely Duval's, Roger's and Dörnenburg methods. 


\section{Chapter 4 \\ Gassing stability of oil and complex oil-paper system under electrical discharge}




\section{Chapter 4}

\section{Gassing stability of oil and complex oil-paper system under electrical discharge}

\subsection{Introduction}

Since gas evolvement deteriorates the dielectric properties of insulating fluid, its ability to resist decomposition under electrical discharge is of paramount importance for the safety of power transformers under operating conditions. Knowledge of the resistance to gassing of insulating fluids under high electrical stress is of upmost important to both electrical-equipments designers and operating engineers.

Failure of liquid filled equipments can be caused by discharge in bubble. Such phenomenon was first observed in the early 1930s in oil filled cables. So far, power equipments are being designed with the aim of minimizing the possibility of formation of gas. The formation of gas bubble in the liquid under electrical stress, results in a stressed liquid-gas interface [29]. If the field stress is high enough, non disruptive or salient discharge will occur with ionization and molecular activation of the gas and liquid molecules. Such discharge is not accompanied by high temperature; therefore the reactions which occur is due to the electrons, the electrical stress, the frequency of the applied voltage, the nature and pressure of the gas phase, the temperature and the chemical composition of the liquid and the physicochemical reactions initiated by the atomized gas phase. There is a direct relation between certain molecules in the fluid and its ability to gas absorption. It is now well established that aromatic molecules affect gassing.

The existing methods to determine the stability of liquid-to-gas formation (resistance to gassing) can be subdivided into two groups. The first is the modified Pirelli method (ASTM D2300 and IEC 60628), which was originally developed for cable oils. Discharges were initiated above the surface of the insulating liquid, involving only the vapor produced by the insulating liquid. This was an important step towards determining the gassing tendency of insulating liquids. However, this method has not been widely 
accepted [30]. The second method to determine the gassing tendency of insulating liquids involves initiating electric discharges directly in a liquid sample in a test cell to simulate faults that occur in operating equipment. Contrary to the first method, it indicates, "whether insulating oils are gas absorbing or gas evolving", which presents a confusing signal to electrical engineers. As long as the gassing of a new or aged insulating oil sample cannot be accurately measured, it is practically impossible to identify the variables that might have caused an increased concentration of fault gases. Consequently, the alternate ASTM Designation D 6180 was developed. This "Standard Test Method for stability of Insulating Oils of Petroleum Origin under Electrical Discharges" can measure the amount of gases evolved by new, in-service aged or reclaimed oils submitted to electrical discharge. While the gassing of insulating oils is considered as a symptom of a potential threat to the operational safety of transformers, its side effects on the purity of oil are generally ignored.

In this testing procedure, the amount of gas evolved by an oil sample as well as the side effects of gassing can be accurately measured. Determining the stray gassing of new oils based upon their chemical composition and monitoring the changes caused by its deterioration in service demonstrate the need to keep the oil in pristine conditions for the lifetime of transformers. These testing can be used for homologation and/or qualification transformer fluids [30]. In relationship with the gassing tendency and the concomitant side effect, fluid can be selected for a specific application.

Insulating oil during service undergoes changes in physical, chemical and electrical properties due to ageing and contamination. The growing amount of impurities like acids, moisture, sludge and polar molecules, are responsible for fast deterioration of oil and affect active service life of the transformer. Without accurately measuring how much gas, charge carriers and colloidal suspensions arise in oil samples submitted to electrical stress; the stability of liquid insulation cannot be reliably determined [22].

Gassing tendency will be analyzed and the influence of pressboard addressed. Besides the testing on new samples, it is planned to perform testing on aged samples too. The influence of decay product and the partnership of oil-pressboard will be highlighted. 


\subsection{Experimental setup}

A Merell-based test cell type, defined in the ASTM Test Method D6180, was used (Figure 4.1). The free electrons are generated by a cylindrical copper electrode $15 \mathrm{~mm}(0.6$ inches) in diameter and $10 \mathrm{~mm}$ long sealed in a $500 \mathrm{ml}$ Erlenmeyer glass. The electrode is placed in the center of the discharge cell and suspended above the oil. The distance between the central electrode and the surface of oil is approximately $25.4 \mathrm{~mm}$ (1 inch) [30].

Before applying the voltage, the discharge cell was vacuumed down to 1 Torr (133 Pa). After vacuum degassing, insulating fluid specimen is subjected to high voltage discharge of $10 \mathrm{kV}$ during the $5 \mathrm{~h}$ test. The pressure increase inside the discharge cell, allows assessing the quantity of gasses evolved [30].

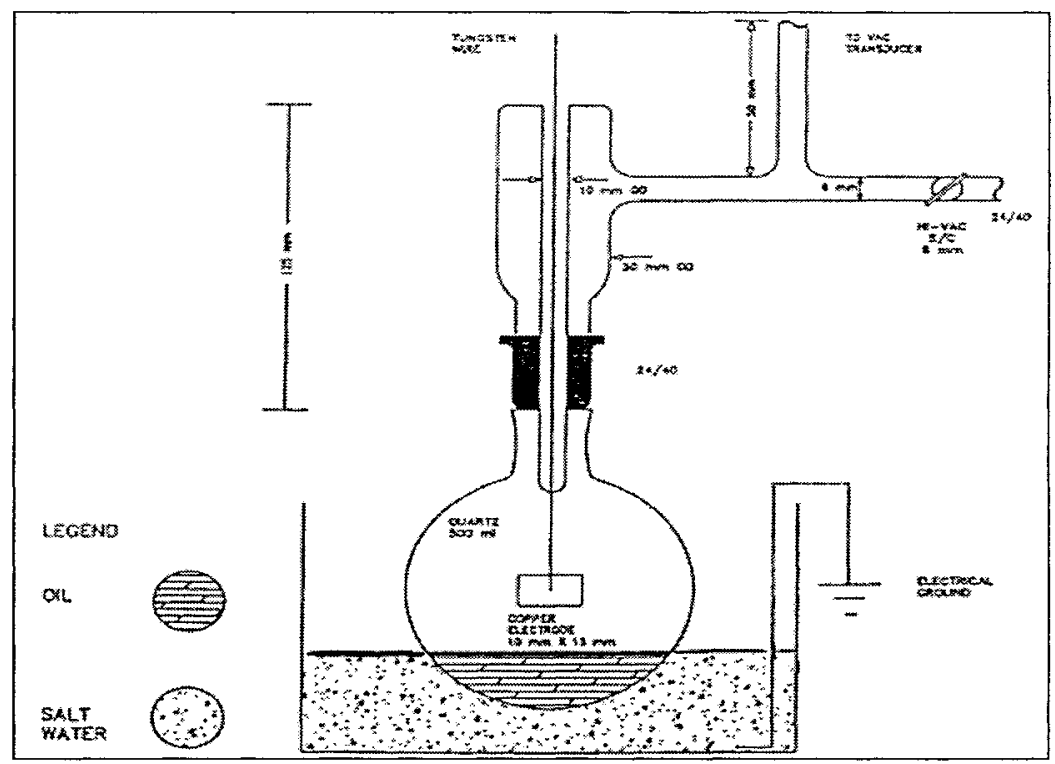

Figure 4.1. Discharge cell according to ASTM Designation D6180 [10].

In these tests, a series of testing were performed on oil without paper. Oil samples were degassed, dehumidified and aged under laboratory condition for extended period of times $(500 \mathrm{~h}, 1000 \mathrm{~h}$, and $2000 \mathrm{~h})$. The second series of tests includes oil samples with different ratios of paper aged under laboratory condition too at various times $(250 \mathrm{~h}, 500 \mathrm{~h}$, $750 \mathrm{~h}$, and $1000 \mathrm{~h}$ ). Different fluids properties such as the Dissolved Decay Products (DDP) [16], Turbidity [15], Interfacial tension (IFT) [14], and Water content [11] were measured before and after voltage application to assess the discharge deleterious impact. 


\subsection{Results and discussions}

Both samples (with and without paper) were submitted to electrical stress according to ASTM D 6180. The pressure increase inside the discharge cell indicates the amount of gases evolved due to the primary decomposition of unstable molecules in the new oil according to Figure 4.2.

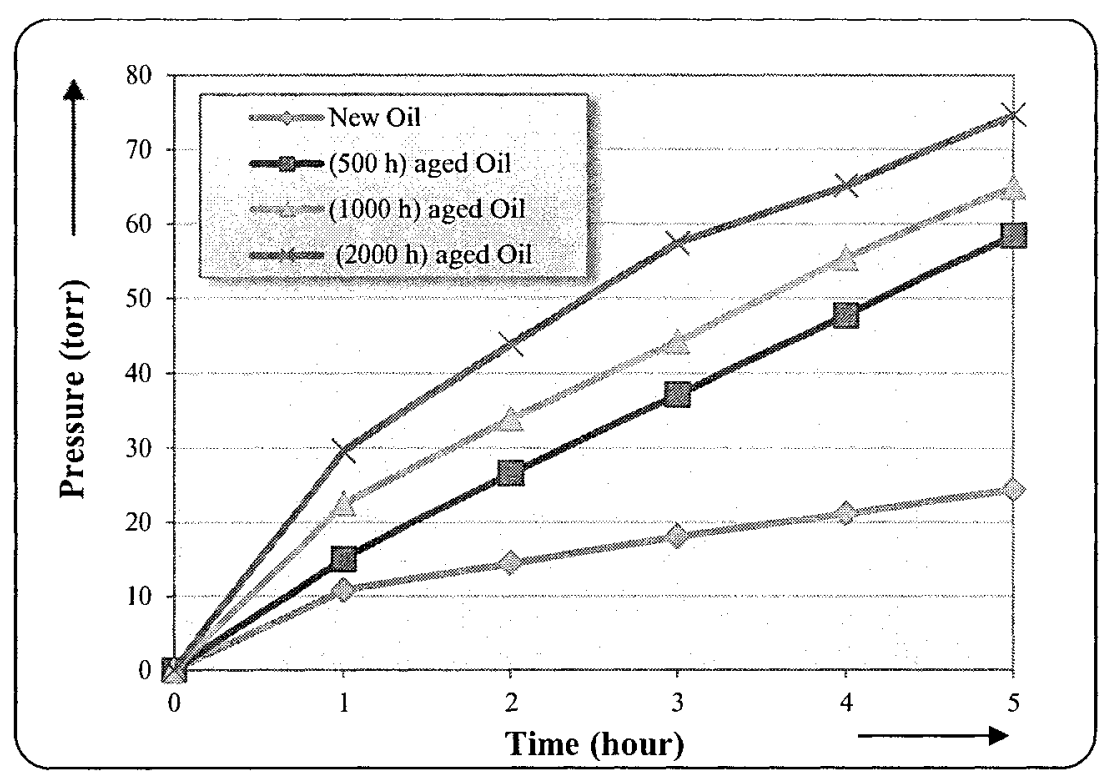

Figure 4.2. Gassing tendency of new and aged oil samples without paper.

Out of this Figure, it can be seen that the pressure increased after the 5 hours test in the oil samples. Obviously, pressure depends on aging rate.

The gassing tendency of 500 hours aged oil-paper with $10 \%$ and $30 \%$ of paper and without paper is summarized in Figure 4.3. In the aged oil-paper samples there was amount of paper inside the oil during aging times, in the case of $500 \mathrm{~h}$ aged oil-papers the paper removed before submitting the sample to stability test.

It should be noted that, $500 \mathrm{~h}$ aged oil-papers reported in Figure 4.3 is not the same with $500 \mathrm{~h}$ aged oil reported in Figure 4.2. 


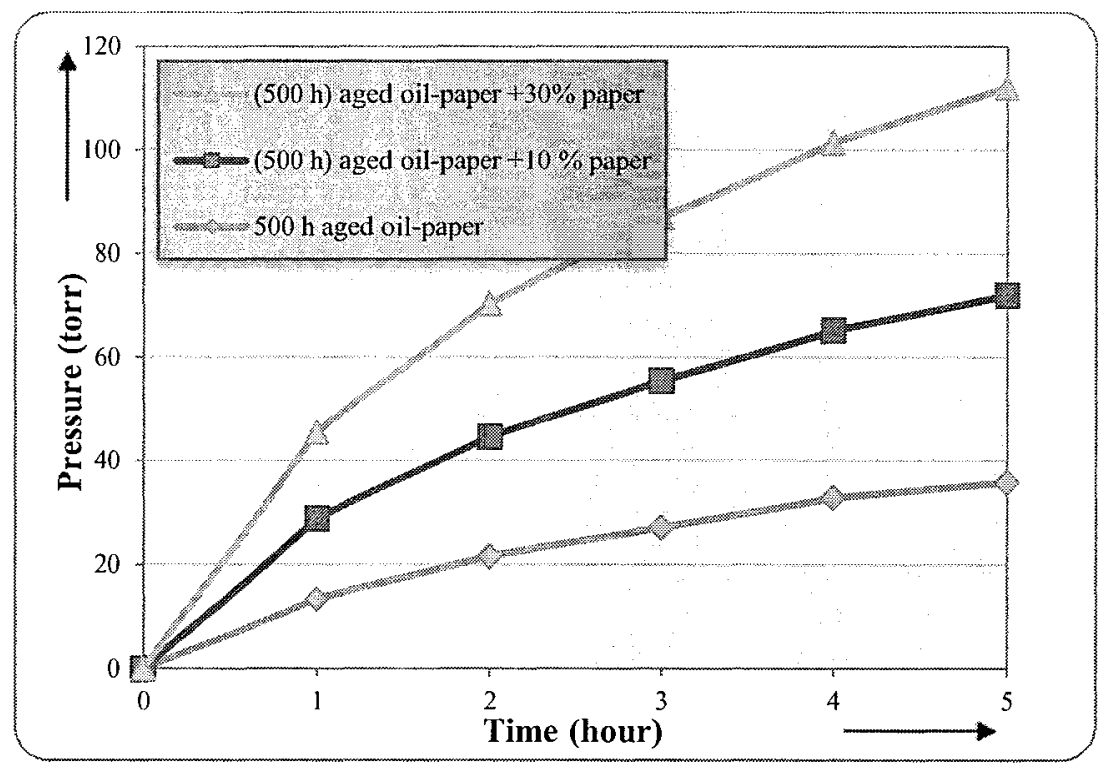

Figure 4.3. Gassing tendency of combined aged oil-paper (with and without paper).

From Figure 4.3, it can also be seen that the pressure increased in the discharge cell when adding paper to oil specimen in the same experimental condition. The higher gassing tendency of oil happens with $30 \%$ of paper. The summary of gassing tests performed under electrical discharge on new and aged oil samples with $10 \%$ of paper is presented in Figure 4.4 .

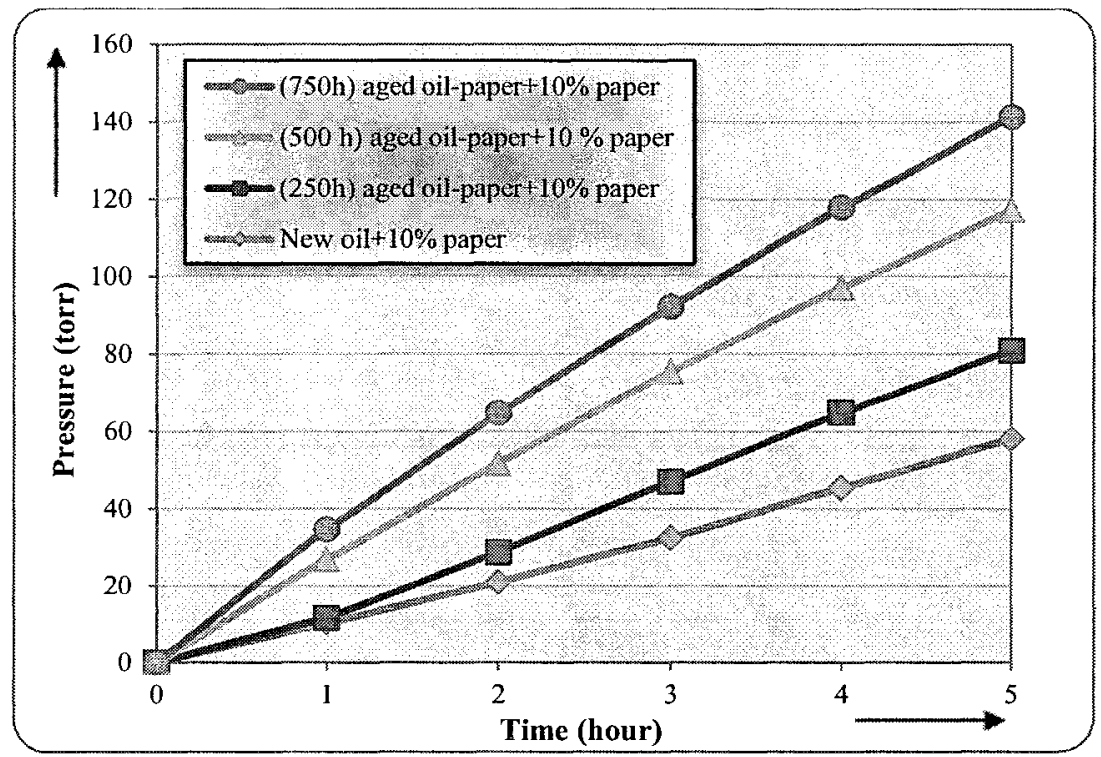

Figure 4.4. The gassing tendency of new and aged oil samples with $10 \%$ of paper as per D6180. 
This Figure indicates that, pressure increases with aging rate. Figure 4.5 shows the gassing tendency of new oil and aged oil $(250 \mathrm{~h}, 500 \mathrm{~h}, 750 \mathrm{~h}$, and $1000 \mathrm{~h})$ partnered with $30 \%$ of paper according to the D6180 stability test.

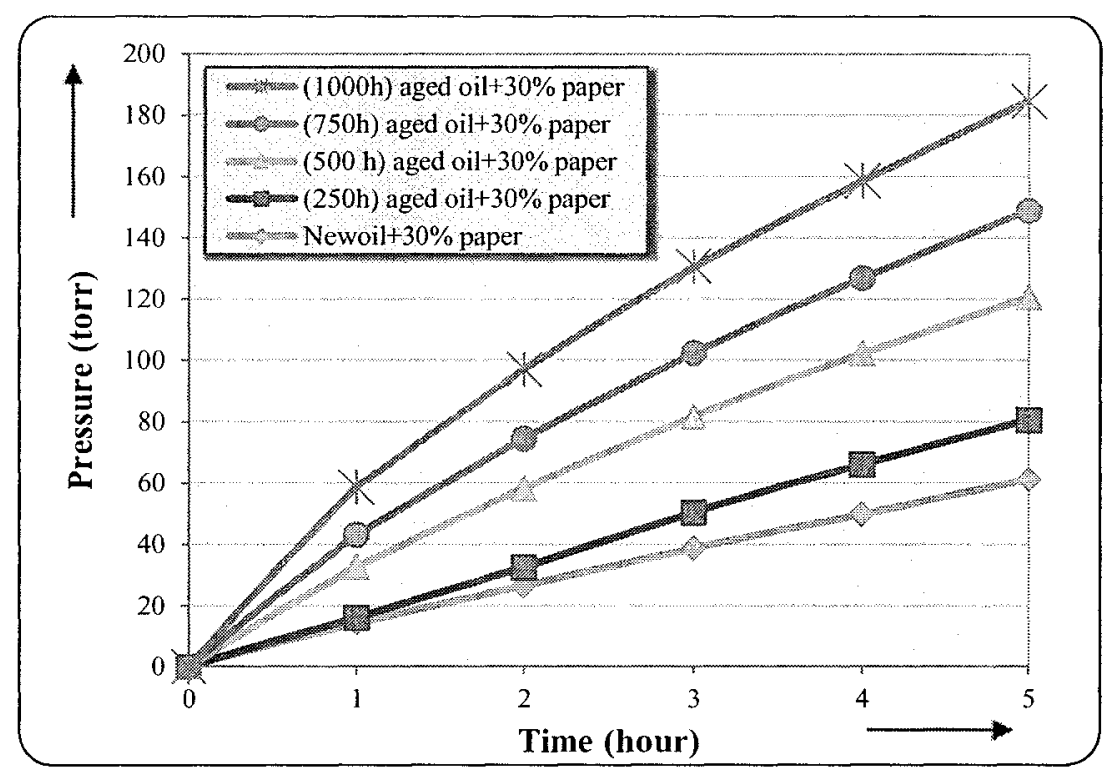

Figure 4.5. The gassing tendencies of new and aged oil samples with $30 \%$ of paper, according to D6180.

Figure 4.5 indicates the increase in gassing tendency of oil samples under electrical stresses by aging rate too. Combining oil with paper and submitting them to stability test result apparently in an increase in the gassing tendency. This might be due to the presence of paper that may lead to formation of more decay products. Recall that contaminants produce gas. After submission of new oil and aged oil to electrical discharge, several physicochemical tests were considered to assess oil's condition:

- Turbidity

- $\quad$ Dissolved decay product (DDP)

- $\quad$ Interfacial tension (IFT)

- Water content

\subsubsection{Turbidity}

Comparison of Turbidity before and after stability test is reported in Figure 4.6. The increase in Turbidity measured by ASTM Test Method D6181 proves the formation of invisible colloidal suspensions that are insoluble in the oil. 


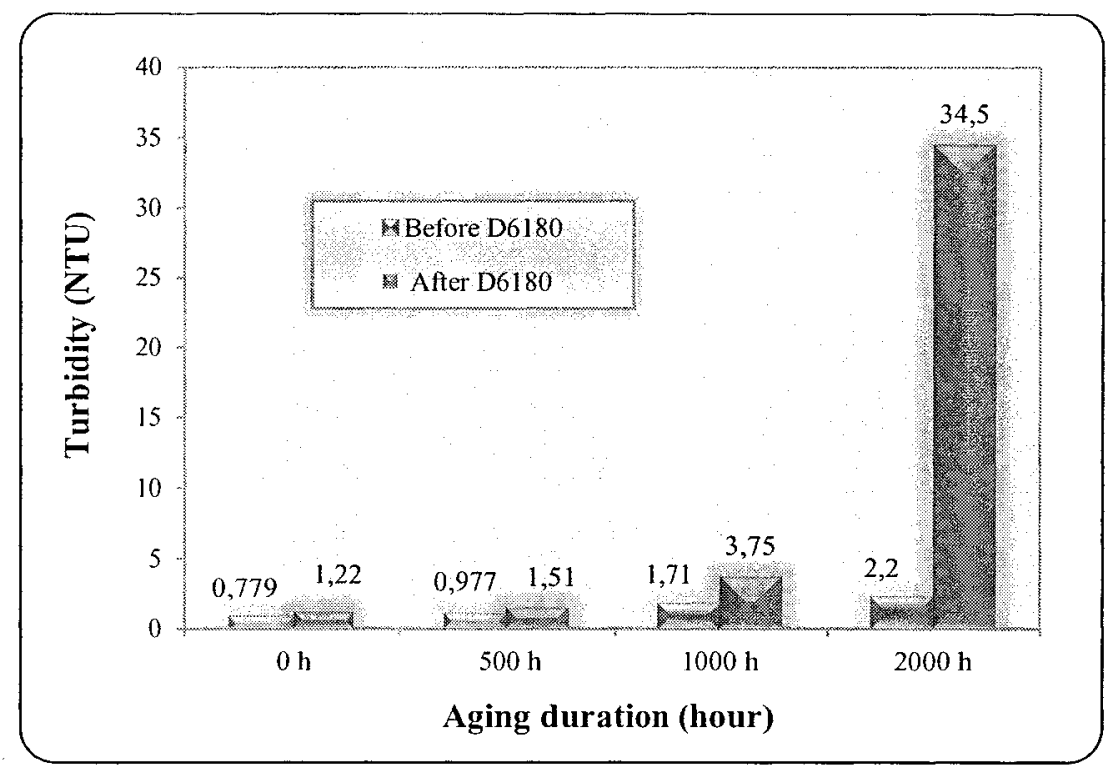

Figure 4.6. Comparison of Turbidity (D6181) before and after D6180 stability test.

\subsubsection{Dissolved Decay Product (DDP)}

The shift of the absorbance curve to longer wavelengths indicates an increased content of dissolved decay products in the oil (Figure 4.7).

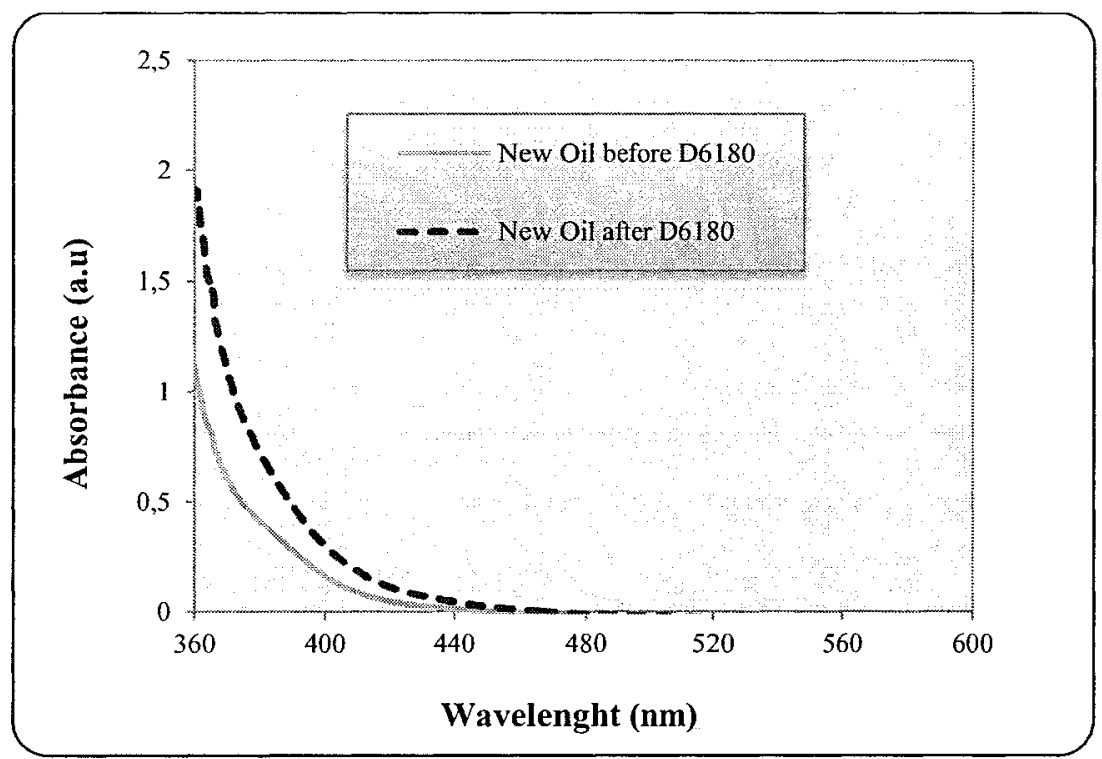

Figure 4.7. Absorbance illustrating the Dissolved Decay Products of new oil before and after D6180. 
The value of DDP after aging increases (Table 4.1) due to the large amounts of free radicals generated by the gassing of oil. Contrary to new oil, the DDP decreases for aged oil after D6180 test. The decrease in DDP after stability test for aged oil samples proves that certain amount of decay products was decomposed to generate gases under random chemical reactions while large insoluble molecules are produced.

Table 4.1. DDP results for new and aged oil samples before and after D6180.

\begin{tabular}{|c|c|c|c|c|}
\hline & New oil & Aged oil(500h) & Aged oil(1000h) & Aged oil(2000h) \\
\hline DDP - (area) before D6180 & 21.4 & 258.91 & 386.16 & 440.09 \\
\hline DDP - (area) after D6180 & 39.29 & 116.78 & 223.84 & 392.08 \\
\hline
\end{tabular}

A comparison between DDP results before and after the stability test are shown in Figure 4.8.

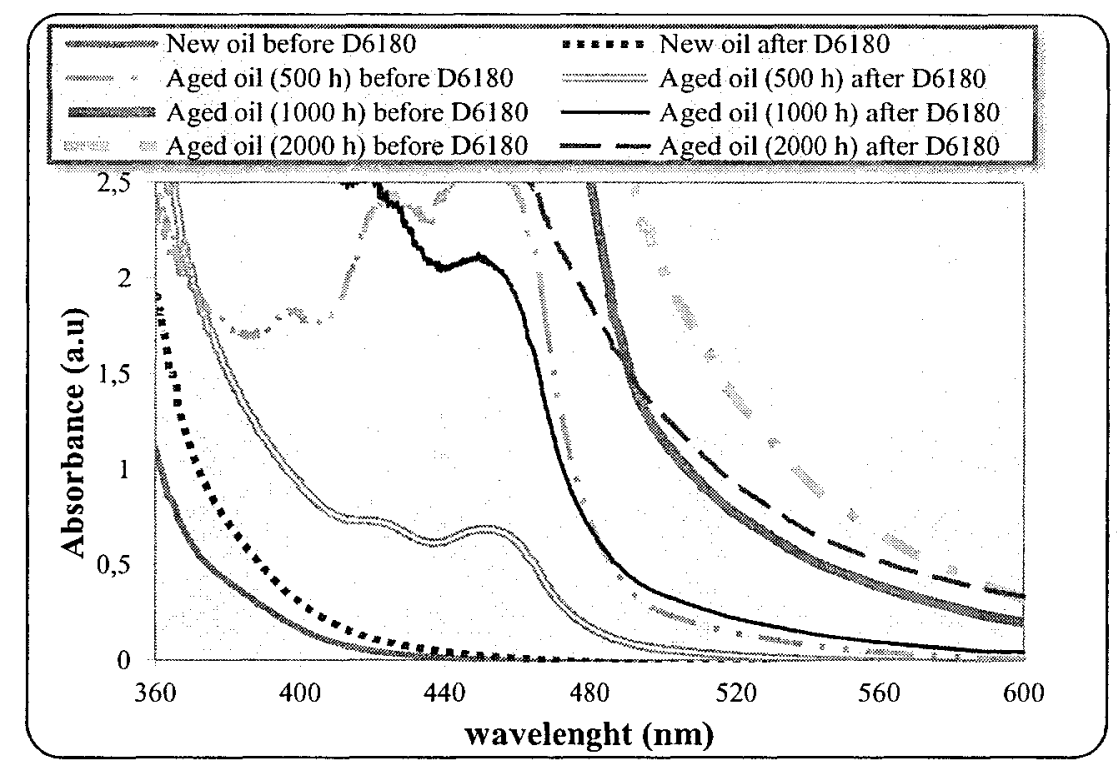

Figure 4.8. Absorbance illustrating the Dissolved Decay Products of new and aged oil samples $(500 \mathrm{~h}, 1000 \mathrm{~h}$ and $2000 \mathrm{~h})$ before and after $\mathrm{D6180}$. 


\subsubsection{Interfacial tension (IFT)}

Table 4.2 shows that the IFT decreases by the presence of trace amounts of large hydrocarbon molecules with polar group, which are the result of degradation of oil due to contaminations [31].

Table 4.2. IFT results assessments before and after D6180.

\begin{tabular}{|c|c|c|c|c|}
\hline & New oil & Aged oil $(500 \mathrm{~h})$ & Aged oil $(1000 \mathrm{~h})$ & Aged oil $(2000 \mathrm{~h})$ \\
\hline IFT before D6180 & 47 & 33.5 & 29.5 & 24.3 \\
\hline IFT after D6180 & 37 & 27.5 & 26.5 & 23.5 \\
\hline
\end{tabular}

A high interfacial tension value indicates the absence of undesirable polar contaminants in the hydrocarbon fluid which means that the fluid is immiscible with water. The impurities in the hydrocarbon fluid encourage the oil to mix with water.

\subsubsection{Water content in transformer oil}

Moisture in oil is measured in parts per million (ppm) using the weight of moisture divided by the weight of oil $(\mu \mathrm{g} / \mathrm{g})$.

The standard test method for measuring water in transformer oil is the ASTM D 1533 test known as the Karl Fischer reaction test. It is based on the reaction of halogens with water in the presence of anhydrous sulfur dioxide. It is widely used because of its high selectivity and sensitivity. There are commercial instruments such as the Mitsubishi Moisture Meter to accomplish the Karl Fischer titration automatically. With these instruments, an oil sample can be directly injected into the reaction unit and the moisture content will be given at the end of the reaction. In the case that the liquid samples contain interfering substances reacting with the reagents, the oil samples are placed in a water vaporizer and then the water vapor is circulated to the reaction unit to be measured [11].

Figure 4.9 shows the water content assessment in oil samples before and after stability test. 


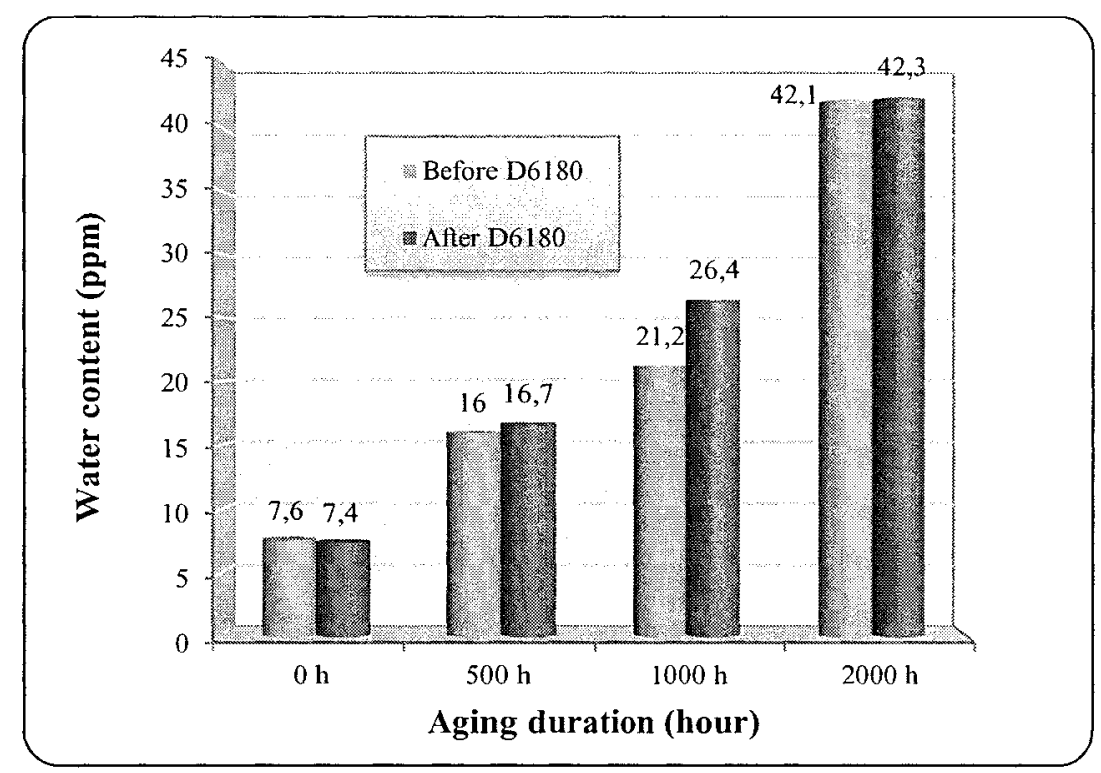

Figure 4.9. Water content assessment in oil sample before and after D6180.

Figure 4.9 clearly illustrates that aging byproducts contribute to increase in moisture content. Water, in minute quantities, is harmful in power equipment because it is attracted to the places of greatest electrical stress and this is where it is the most dangerous. Oxidation process is likely to take place during cross-linking of the oil.

Electrical discharge along with the oxidation release also moisture in the oil (OH. + $\mathrm{RH} \rightarrow \mathrm{H}_{2} \mathrm{O}+\mathrm{R}$.), as assessed by Karl Fisher titration. Coulometric titration by Karl Fischer represents a credible method to access the moisture content of insulation oil and paper/pressboard. However, oil additives and ageing products may interact with the Karl Fischer reagent, especially if direct titration is used [32].

\subsection{Summary}

Fast, inexpensive and reliable laboratory testing procedures developed by ASTM (D 6802 and D 6181) have been used to monitor decay products as trace impurities before and after the stability test under electrical discharges (D6180). These testing procedures can also be used to assess the capability of any fluid sample to resist decomposition, including reclaimed oils effectiveness [22].

From the results reported in Tables 4.3 and 4.4, the following conclusions may be drawn : 
$>$ The properties of new oil samples (Turbidity, DDP, IFT and Water content) indicate that aged oil contain more substantial amount of residual polar compounds or unstable hydrocarbon and volatile molecules that affect the gassing tendency.

$>$ The value of DDP after stability test, increases for new oil due to the large amounts of free radicals generated by the gassing of oil. At the same time, the turbidity goes also up due to the secondary chemical reactions between the broken hydrocarbon chains.

$>$ Aged oils basically contain dissolved impurities, mainly consisting of decay products ionized, free radicals, gas, and oxidized molecules .

Aged oils show a decrease in the DDP after D 6180 testing. This may have been due to the evaporation of certain unstable and volatile constituents of the oils during vacuum degassing (before voltage application).

$>$ It is observed from Table 4.4 that, IFT results decreased after stability test for new oil and the same aged oil samples.

Table 4.3. Insulating fluid samples assessment before D6180 stability test.

\begin{tabular}{|l|c|c|c|c|}
\hline & New oil & Aged oil(500h) & Aged oil(1000h) & Aged oil(2000h) \\
\hline Turbidity D 6181 (NTU) & 0.779 & 0.977 & 1.71 & 2.2 \\
\hline DDP - D 6802 (area) & 21.4 & 258.91 & 386.16 & 440.09 \\
\hline Interfacial Tension (IFT) & 47 & 33.5 & 29.5 & 24.3 \\
\hline Water content (ppm) & 7.6 & 16 & 21.2 & 42.1 \\
\hline
\end{tabular}

Table 4.4. Insulating fluid samples assessment after D6180 stability test.

\begin{tabular}{|c|c|c|c|c|}
\hline & New oil & Aged oil(500h) & Aged oil(1000h) & Aged oil(2000h) \\
\hline Turbidity D 6181 (NTU) & 1.22 & 1.51 & 3.75 & 34.5 \\
\hline DDP - D 6802 (area) & 39.29 & 116.78 & 223.84 & 392.08 \\
\hline Interfacial Tension (IFT) & 37 & 27.5 & 26.5 & 23.5 \\
\hline Water content (ppm) & 7.4 & 16.7 & 26.4 & 42.3 \\
\hline
\end{tabular}




\section{Chapter 5}

\section{Impact of aging by-products on DGA techniques}




\section{Chapter 5}

\section{Impact of aging by-products on DGA techniques}

\subsection{Introduction}

Many key properties, providing a "picture" of the fluid or the solid insulation "health", have been studied, normalized in standards and finally taken as criterion for monitoring power transformers.

Since all these methods are based on heuristic in nature and not based on scientific formulation, the applicant and his German collaborators have recently proposed a combined DGA diagnostic that helps reducing the risk of mistaken diagnostics and enhance accuracy [6]. Recent progress in the applicant's laboratory [30] has shown that contaminants produce gases as all.

Similar to a blood test or scanner examination of human body, DGA can give early diagnosis and increase the chances of finding the appropriate cure. The main objective of this research project is to investigate how aging by product might affect DGA testing. The proposed research was carried out using the following methods that have been demonstrated to be both effective and successful in reputable research laboratories worldwide including the ISOLIME.

The oil samples was aged at different aging times from 500 to 1000 hours which simulate long time service condition due to the used severe aging conditions.

\subsection{Experimental setup}

\subsubsection{Reclamation by Fuller's Earth (FE)}

Oil reclamation has an important role in the preventive maintenance of transformer. The dissolved impurities, mainly consisting of decay products ionized (charge carriers), free radicals, gas, and oxidized molecules, which multiply in the useful life insulating fluids for transformers can be eliminated by passing the oil through a bed of Fuller's earth. Fuller's earth is a mined product (a clay type material with a composition of alumina, silica, iron oxides, lime, and magnesia in various proportions) which, after drying and processing by 
acid activation, is usually supplied as a fine powder. The colour can be grey, buff, green, brown or blue. Fuller's Earth removes both moisture and neutralizes carboxylic acids [33].

In order to investigate the influence of aging by-products, part of the aged oil samples were reclaimed with Fuller's Earth. The reclamation rejuvenates the transformer oil by eliminating contaminants formed due to entry of foreign particles, oxidation of oil and insulation deterioration, sludge formation, thermal cracking etc. Free radicals and decay products concentration is indicative of poor oil quality as suggested by its high power factor [30].

Data reported in Table 5.1 indicates comparison of dissolved gas extracted from the samples before and after reclamation.

Table 5.1. Dissolved gas extracted from the samples before $\&$ after reclamation.

\begin{tabular}{|c|c|c|c|c|c|}
\hline Gas & $\begin{array}{l}\text { New } \\
\text { Oil }\end{array}$ & $\begin{array}{l}\text { Aged oil } \\
(500 \mathrm{~h})\end{array}$ & $\begin{array}{c}\text { Reclaimed } \\
\text { aged oil }(500 \mathrm{~h})\end{array}$ & $\begin{array}{l}\text { Aged oil } \\
(1000 \mathrm{~h})\end{array}$ & $\begin{array}{c}\text { Reclaimed } \\
\text { aged oil }(1000 \mathrm{~h})\end{array}$ \\
\hline Hydrogen $\left(\mathrm{H}_{2}\right)$ & 10 & 10 & 10 & 10 & 10 \\
\hline Carbon Monoxide(CO) & 55 & 55 & 10 & 63 & 7 \\
\hline Methane( $\left.\mathrm{CH}_{4}\right)$ & 5 & 7 & 5 & 5 & 5 \\
\hline Carbon Dioxide $\left(\mathrm{CO}_{2}\right)$ & 373 & 724 & 610 & 968 & 630 \\
\hline Ethylene $\left(\mathrm{C}_{2} \mathrm{H}_{4}\right)$ & 2 & 8 & 4 & 2 & 2 \\
\hline Ethane $\left(\mathrm{C}_{2} \mathrm{H}_{6}\right)$ & 2 & 4 & 2 & 4 & 2 \\
\hline Acetylene $\left(\mathrm{C}_{2} \mathrm{H}_{2}\right)$ & 2 & 2 & 2 & 2 & 2 \\
\hline Nitrogen $(\mathrm{N})$ & 57500 & 61100 & 59800 & 59800 & 61200 \\
\hline Oxygen + Argon & 25500 & 28800 & 31600 & 29300 & 32000 \\
\hline Total dissolved gas & 83449 & 90710 & 92043 & 90154 & 93858 \\
\hline Total combustible gas* & 76 & 86 & 33 & 86 & 28 \\
\hline
\end{tabular}

* Total dissolved combustible gas $=\mathrm{Sum}$ of $\mathrm{H}_{2}, \mathrm{CH}_{4}, \mathrm{C}_{2} \mathrm{H}_{6}, \mathrm{C}_{2} \mathrm{H}_{4}, \mathrm{C}_{2} \mathrm{H}_{2}$, and $\mathrm{CO}(\mathrm{ppm})$.

According to this table, the amount of total combustible gases seems to be dependent on aging rate of oil samples. In this table, it can be observed that after reclamation of aged oils, the volume of total combustible gases decreased. It can be seen too that the value of total dissolved gases are not affected by aging rate. The oil properties before reclamation are summarized in Table 5.2. 
Table 5.2. Summary the oil properties before reclamation process.

\begin{tabular}{|l|c|c|c|}
\hline & New oil & $500 \mathrm{~h}$ aged oil & $1000 \mathrm{~h}$ aged oil \\
\hline Turbidity(NTU) & 0.779 & 0.977 & 2.45 \\
\hline DDP(area) & 3.96 & 241.47 & 390.96 \\
\hline Water content & 3.2 & 14.8 & 26.6 \\
\hline IFT & 34.2 & 25.1 & 21.9 \\
\hline Acidity & 0.02921 & 0.02805 & 0.14025 \\
\hline
\end{tabular}

The increase in turbidity, DDP and water content proves the formation of colloidal suspensions in the oil sample after aging. One way to detect oil degradation is through change in its acidity (neutral number - NN) and IFT. The comparative results of aged oil sample after reclamation are summarised in Figure 5.1.

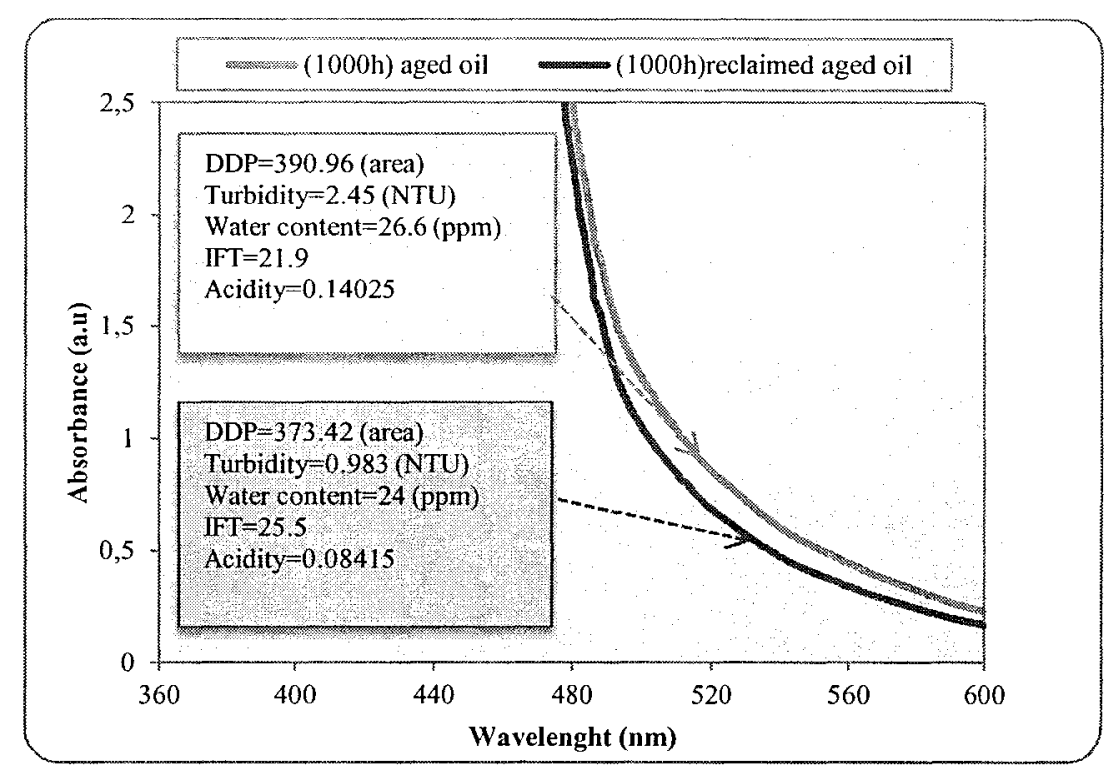

Figure 5.1. Comparative summary of $1000 \mathrm{~h}$ aged oil properties before and after reclamation.

From this Figure, it can be observed that the DDP after reclamation, is lowered since some impurities (dissolved in the oil) were removed during the reclammation of oil sample. 


\subsubsection{Partial discharge}

Partial discharges were initiated in the liquids using a test cell consisting of a cube with needle-plate electrode configuration. This discharge partially bridges the insulation between electrodes. Experiments carried out on new and aged oil (Tables 5.3) show an increase in the total combustible gases amount. This amount increases with aging duration time, probably due to the contribution of soluble and insoluble decay products.

Table 5.3. Dissolved gases extracted from the samples after application of PD.

\begin{tabular}{|l|c|c|c|}
\hline Gas & New Oil & Aged oil (500h) & Aged oil (1000h) \\
\hline Hydrogen( $\left.\mathrm{H}_{2}\right)$ & 10 & 10 & 10 \\
\hline Carbon Monoxide(CO $)$ & 17 & 24 & 27 \\
\hline Methane $\left(\mathrm{CH}_{4}\right)$ & 5 & 5 & 5 \\
\hline Carbon Dioxide $\left(\mathrm{CO}_{2}\right)$ & 565 & 656 & 997 \\
\hline Ethylene $\left(\mathrm{C}_{2} \mathrm{H}_{4}\right)$ & 2 & 8 & 5 \\
\hline Ethane $\left(\mathrm{C}_{2} \mathrm{H}_{6}\right)$ & 2 & 3 & 4 \\
\hline Acetylene( $\left.\mathrm{C}_{2} \mathrm{H}_{2}\right)$ & 2 & 4 & 15 \\
\hline Nitrogen(N) & 61200 & 60200 & 60200 \\
\hline Oxygen +Argon & 32000 & 31100 & 30800 \\
\hline Total dissolved gas & 93793 & 92011 & 92063 \\
\hline Total combustible gas* & 38 & 54 & 66 \\
\hline
\end{tabular}

Table 5.4 provides diagnostics predicted from our Labview-based program, from the analysis of gases extracted from new and aged oil samples after partial discharge application.

Table 5.4. DGA diagnostic assessment's after application of partial discharge.

\begin{tabular}{|c|c|c|c|}
\hline & New oil & $500 \mathrm{~h}$ aged oil & loo0 h aged oil \\
\hline Duval & Tracking \&arcing & High Energy Discharge & High Energy Discharge \\
\hline Dörnenburg & Not identified & No fault & Not identified \\
\hline Roger's & No fault & No fault & No fault \\
\hline
\end{tabular}

Partial discharge voltage is sensitive to both chemical composition and purity of insulating oils. Dissolved gases extracted from aged oil $(1000 \mathrm{~h})$ and reclaimed aged oil 
(1000 h) after PD application reported in Table 5.5 and their results predicted by our Labview program, are shown in Table 5.6.

Table 5.5. Dissolved gases extracted from the samples after application of PD.

\begin{tabular}{|l|c|c|}
\hline Gas & Aged oil $(1000 \mathrm{~h})$ & Reclaimed aged oil $(1000 \mathrm{~h})$ \\
\hline Hydrogen( $\left.\mathrm{H}_{2}\right)$ & 10 & 10 \\
\hline Carbon Monoxide(CO) & 27 & 28 \\
\hline Methane $\left(\mathrm{CH}_{4}\right)$ & 5 & 5 \\
\hline Carbon Dioxide $\left(\mathrm{CO}_{2}\right)$ & 997 & 717 \\
\hline Ethylene $\left(\mathrm{C}_{2} \mathrm{H}_{4}\right)$ & 5 & 5 \\
\hline Ethane $\left(\mathrm{C}_{2} \mathrm{H}_{6}\right)$ & 4 & 3 \\
\hline Acetylene $\left(\mathrm{C}_{2} \mathrm{H}_{2}\right)$ & 15 & 11 \\
\hline Nitrogen(N) & 60200 & 59600 \\
\hline Oxygen + Argon & 30800 & 30400 \\
\hline Total dissolved gas & 92063 & 90779 \\
\hline Total combustible gas* & 66 & 62 \\
\hline
\end{tabular}

Table 5.6. DGA diagnostic assessment's after application of partial discharge stress.

\begin{tabular}{|l|c|c|}
\hline Duval & $1000 \mathrm{~h}$ aged oil & $1000 \mathrm{~h}$ Reclaimed aged oil \\
\hline Dömenburg & High Energy Discharge & High Energy Discharge \\
\hline Roger's & Not identified & Not identified \\
\hline
\end{tabular}

Apparently, according to Table 5.6, DGA diagnostics predicted by Duval's triangle, Roger's and Dörnenburg ratio methods are the same for aged and reclaimed aged oil (1000 h). Table 5.7 presents some properties of new and aged oil after partial discharge application.

Table 5.7. Summary of the fluids properties submitted to partial discharge stress.

\begin{tabular}{|c|c|c|c|c|c|}
\hline & Turbidity & DDP & $\begin{array}{c}\text { Water } \\
\text { content }\end{array}$ & IFT & Acidity \\
\hline New oil & 1.15 & 21.22 & 5.2 & 32.9 & 0.02805 \\
\hline $500 \mathrm{~h}$ aged oil & 0.708 & 261.52 & 22.5 & 23.9 & 0.02805 \\
\hline $1000 \mathrm{~h}$ aged oil & 2.62 & 391.22 & 25 & 22 & 0.14025 \\
\hline
\end{tabular}

Aged oil (1000 hours) also reveals the side effects of gassing due to the secondary chemical reactions between broken hydrocarbons with increase in DDP and Turbidity. The 
relative content of DDP of the reclaimed aged fluid samples was numerically characterized from the absorbance curves. The obtained results are summarized in Figure 5.2.

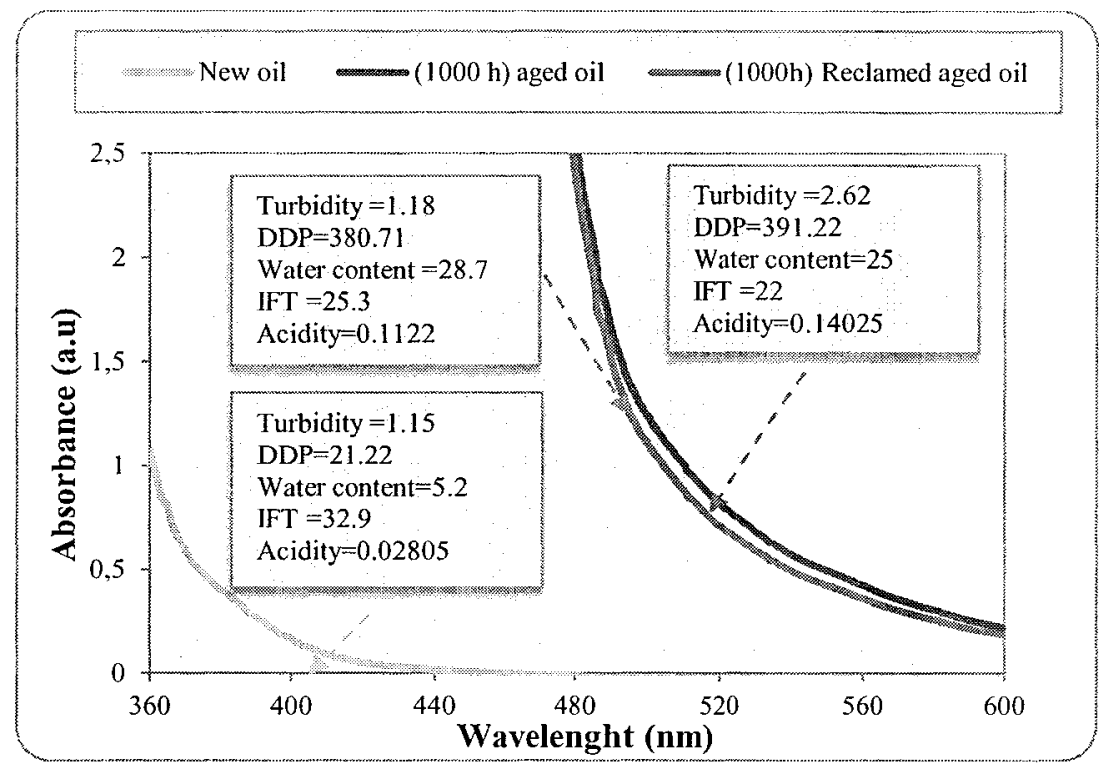

Figure 5.2. Summary of the fluids properties after Partial discharge (PD) application.

From Figure 5.2, it can be observed that DDP (area) increase with aging and decrease after reclamation. The values of Turbidity and Acidity test after PD application to the oil samples increased with aging rate and decrease with reclamation too. On the other hand, the amount of IFT decreased with aging of oil samples and increased after reclamation.

\subsubsection{Breakdown}

To simulate incipient electrical failure, oil samples were submitted to 50 breakdown tests according to ASTM D877 at room temperature. The voltage was raised at $2 \mathrm{kV} / \mathrm{s}$. The results of dissolved gases extracted after 50 breakdown tests applications are reported in Table 5.8 . 
Table 5.8. Dissolved gases extracted from the samples after application of $\mathbf{5 0}$ breakdown tests.

\begin{tabular}{|l|c|c|c|}
\hline Gas & New Oil & Aged oil (500h) & Aged oil (1000h) \\
\hline Hydrogen $\left(\mathrm{H}_{2}\right)$ & 10 & 10 & 10 \\
\hline Carbon Monoxide(CO $)$ & 15 & 23 & 22 \\
\hline Methane $\left(\mathrm{CH}_{4}\right)$ & 5 & 5 & 5 \\
\hline Carbon Dioxide $\left(\mathrm{CO}_{2}\right)$ & 517 & 799 & 873 \\
\hline Ethylene $\left(\mathrm{C}_{2} \mathrm{H}_{4}\right)$ & 2 & 3 & 4 \\
\hline Ethane $\left(\mathrm{C}_{2} \mathrm{H}_{6}\right)$ & 2 & 2 & 3 \\
\hline Acetylene $\left(\mathrm{C}_{2} \mathrm{H}_{2}\right)$ & 8 & 9 & 15 \\
\hline Nitrogen $(\mathrm{N})$ & 61900 & 62900 & 60100 \\
\hline Oxygen + Argon & 32600 & 31800 & 31000 \\
\hline Total dissolved gas & 95059 & 95551 & 92032 \\
\hline Total combustible gas* & 42 & 52 & 59 \\
\hline
\end{tabular}

The diagnostic for the oil samples depicted in Table 5.8, predicted by the DGA test method implemented in our software, are summarized in Table 5.9.

Table 5.9. DGA after application of 50 breakdown tests in the oil samples.

\begin{tabular}{|c|c|c|c|}
\hline & New oil & $500 \mathrm{~h}$ aged oil & $1000 \mathrm{~h}$ aged oil \\
\hline Duval & $\begin{array}{c}\text { Tracking } \\
\text { \&arcing }\end{array}$ & $\begin{array}{c}\text { High Energy } \\
\text { Discharge }\end{array}$ & High Energy \\
\hline Dörnenburg & Not identified & Not identified & Not identified \\
\hline Roger's & No fault & Arcing & Arcing \\
\hline
\end{tabular}

Table 5.9 shows the influence of aging by product and breakdown application on the DGA analyses.

In order to lay more emphasize on the influence of decay products, part of aged oil was reclaimed with Fuller's Earth, degassed and submitted to 50 breakdown tests. The interpretation of fault gases produced by both oils is shown in Table 5.10. 
Table 5.10. Dissolved gases extracted from the samples after application of $\mathbf{5 0}$ breakdown tests.

\begin{tabular}{|c|c|c|}
\hline Gas & Aged oil (1000 h) & Reclaimed aged oil $(1000 \mathrm{~h})$ \\
\hline Hydrogen $\left(\mathrm{H}_{2}\right)$ & 10 & 10 \\
\hline Carbon Monoxide(CO ) & 22 & 20 \\
\hline Methane $\left(\mathrm{CH}_{4}\right)$ & 5 & 5 \\
\hline Carbon Dioxide $\left(\mathrm{CO}_{2}\right)$ & 873 & 676 \\
\hline Ethylene $\left(\mathrm{C}_{2} \mathrm{H}_{4}\right)$ & 4 & 2 \\
\hline Ethane $\left(\mathrm{C}_{2} \mathrm{H}_{6}\right)$ & 3 & 2 \\
\hline Acetylene $\left(\mathrm{C}_{2} \mathrm{H}_{2}\right)$ & 15 & 2 \\
\hline Nitrogen(N) & 60100 & 59100 \\
\hline Oxygen + Argon & 31000 & 30900 \\
\hline Total dissolved gas & 92032 & 90041 \\
\hline Total combustible gas* & 59 & 41 \\
\hline
\end{tabular}

Table 5.11 indicates a comparison of DGA results for 1000 hours aged oil and reclaimed aged oil after application of 50 breakdown tests in the oil specimens.

Table 5.11. DGA results after application of 50 breakdown tests in the oil samples.

\begin{tabular}{|l|c|c|}
\hline & $1000 \mathrm{~h}$ aged oil & $1000 \mathrm{~h}$ Reclaimed aged oil \\
\hline Duval & $\begin{array}{c}\text { High Energy } \\
\text { Discharge }\end{array}$ & In paper $: \mathrm{T}>300^{\circ} \mathrm{C}$ and In Oil $: \mathrm{T}>700^{\circ} \mathrm{C}$ \\
\hline Dörnenburg & Not identified & No fault \\
\hline Roger's & Arcing & Arcing \\
\hline
\end{tabular}

The theoretical premises that, oil born decay products contribute to the oil gassing, is confirmed again looking at the total amount of gas generated. The DGA reported in Table 5.10, predicted different incipient failures, apparently influenced by oil born decay products.

Table 5.12 shows the effect of breakdown on the transformer oil. In this case, some characteristics of oil investigated before and after reclamation are reported. 
Table 5.12. Some oil properties submitted to breakdown test before and after reclamation.

\begin{tabular}{|l|c|c|c|c|c|}
\hline & New oil & $500 \mathrm{~h}$ aged & $500 \mathrm{~h}$ Reclaimed & $1000 \mathrm{~h}$ aged & $1000 \mathrm{~h}$ Reclaimed \\
\hline Turbidity (NTU) & 1.33 & 1.11 & 0.636 & 2.38 & 1.07 \\
\hline DDP (area) & 5.24 & 261.99 & 247.03 & 389.06 & 367.66 \\
\hline Water content & 9.7 & 24.6 & 28.3 & 24.6 & 28.4 \\
\hline IFT & 32.5 & 26 & 29 & 20.5 & 26 \\
\hline Acidity & 0.02805 & 0.08415 & 0.1122 & 0.08415 & 0.0561 \\
\hline
\end{tabular}

Determining the turbidity and DDP of the oil specimen after the breakdown test, and comparing them with those reported in Table 5.12, allow assessing the outcome of random secondary chemical reactions between large oil-born free radicals. It is interesting to note that all properties of oil are affected by breakdown.

\subsubsection{Thermal stress}

Thermal stress is a factor that can seriously affect the reliability of the oils and the life of transformers. Even in normal operation, gases can be generated by service overheating or overloading.

Transformer oil will age rapidly at high temperatures; while moisture acts as a catalyst. There are also other catalysts present in a transformer that increases the speed of oil degradation. These include copper, paint, varnish and oxygen. The principal mechanism of transformer oil aging is oxidation, which results in the buildup of acids and other polar compounds. These oxidation products will have a deleterious effect on the insulation degradation processes. Transformer oil, when subjected to thermal and electrical stresses in an oxidizing atmosphere, gradually loses its stability decomposed and oxidized; its acidity increases and finally begins to produce sludge [34].

To perform this experiment in the laboratory condition, a special test cell has been designed (Figure 5.3). The aim of the test is to simulate thermal stress based on the local overheating of the fluid. Two values of the heating current ( $3 \mathrm{~A}$ and $20 \mathrm{~A}$ ) allow simulating two thermal faults (for low temperature $\left(\mathrm{T}<300^{\circ} \mathrm{C}\right)$ and high temperature $(300<\mathrm{T}<700$ ${ }^{\circ} \mathrm{C}$ ). The prototype consists of a borosilicate beaker, and a cover of Teflon. Temperature around the wire is assumed to be constant and measured by a $\mathrm{NiCr}-\mathrm{Ni}$ probe. The heating 
resistance has the property to change its resistivity linearly in a wide temperature range up to $550^{\circ} \mathrm{C}$. The heating current of the resistance is provided by a secondary low voltage transformer. While the temperature of the wire is adjusted by a voltage regulator connected to the secondary circuit. A funnel is installed above the heating wire, which allows gas generated to go directly to the measuring pipette. By measuring the voltage and current, the average temperature can be calculated. This arrangement can generate a fluid temperature above $500{ }^{\circ} \mathrm{C}$. Fluids subjected to tests $(800 \mathrm{ml})$ were locally overheated for 30 minutes under a constant current of 20 amperes rms. Temperatures reached values close to $250^{\circ} \mathrm{C}$. A second series of testing were performed on oil samples under a constant current of 3 amperes rms.

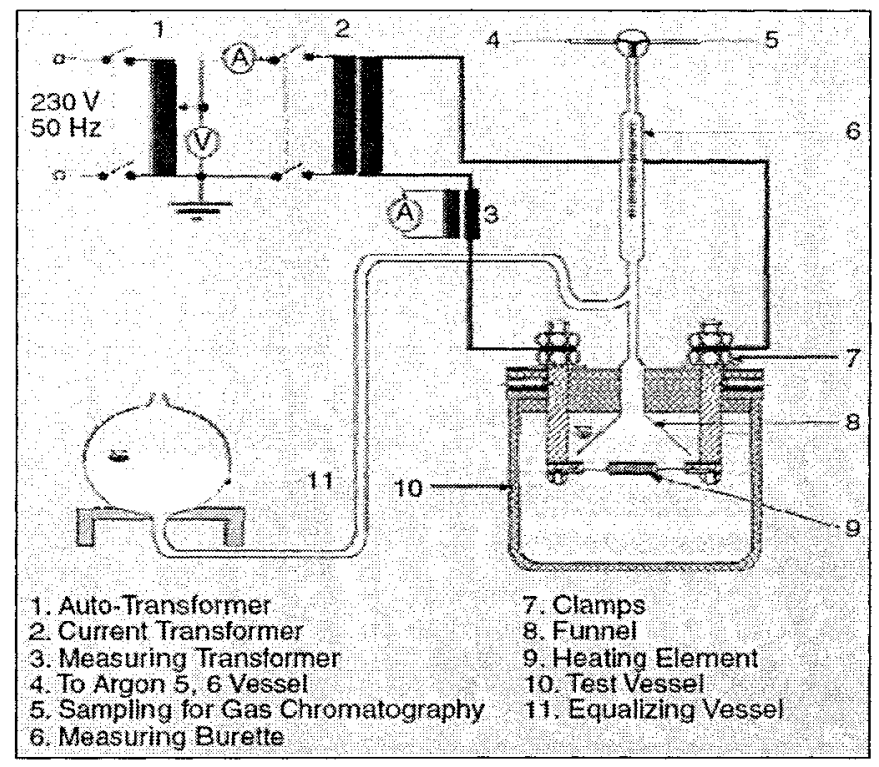

Figure 5.3. Test vessel and setup for local heating of the insulating liquid [35].

Under normal operating conditions, the temperature of oil is usually below $60{ }^{\circ} \mathrm{C}$ above ambient. In such circumstances mainly the rotational and vibrational energies of hydrocarbon chains are excited, while the split of a covalent bond takes place only when an electronic excitation level is reached. However, weakly bonded molecules can occasionally accumulate sufficient energy to reach the electronic excitation level and decompose to form, initially, two free radicals which can then react as discussed above [22]. 
In addition, high temperature accelerates/catalyzes oxidation process, increases the mobility of free radicals generated by the gassing of oil, and thus promotes the random secondary chemical reactions that precede the formation of decay products [22].

\subsubsection{Thermal faults}

The decomposition of mineral oil from $150{ }^{\circ} \mathrm{C}$ to $500{ }^{\circ} \mathrm{C}$ produces relatively large quantities of the low molecular weight gases, such as hydrogen $\left(\mathrm{H}_{2}\right)$ and methane $\left(\mathrm{CH}_{4}\right)$, and trace quantities of the higher molecular weight gases ethylene $\left(\mathrm{C}_{2} \mathrm{H}_{4}\right)$ and ethane $\left(\mathrm{C}_{2} \mathrm{H}_{6}\right)$. As the fault temperature in mineral oil increases to modest temperatures, the hydrogen concentration exceeds that of methane, but now the temperatures are accompanied by significant quantities of higher molecular weight gases - first ethane, and then ethylene. At the upper end of the thermal fault range, increasing quantities of hydrogen and ethylene and traces of acetylene $(\mathrm{C} 2 \mathrm{H} 2)$ may be produced [5].

In contrast with the thermal decomposition of oil, the thermal decomposition of cellulose and other solid insulation produces carbon monoxide $(\mathrm{CO})$, carbon dioxide $\left(\mathrm{CO}_{2}\right)$, and water vapour at temperatures much lower than that for decomposition of oil and at rates exponentially proportional to the temperature. Because the paper begins to degrade at lower temperatures than the oil, its gaseous by products are found at normal operating temperatures in the transformer. A GSU (Generator Step-Up) transformer, for example, that operates at or near nameplate rating will normally generate several hundred microliters/liter

$(\mathrm{ppm})$ of $\mathrm{CO}$ and several thousand microliters/liter $(\mathrm{ppm})$ of $\mathrm{CO}_{2}$ without excessive hot spots.

The last series of testing concern thermal stress (20 A) current applications reported in Table 5.13. 
Table 5.13. Dissolved gases extracted from the samples after thermal stress $(20 \mathrm{~A})$.

\begin{tabular}{|l|c|c|c|}
\hline Gas & New Oil & Aged oil $(500 \mathrm{~h})$ & Aged oil (1000h) \\
\hline Hydrogen( $\left.\mathrm{H}_{2}\right)$ & 10 & 10 & 10 \\
\hline Carbon Monoxide(CO $)$ & 18 & 20 & 31 \\
\hline Methane $\left(\mathrm{CH}_{4}\right)$ & 5 & 5 & 5 \\
\hline Carbon Dioxide $\left(\mathrm{CO}_{2}\right)$ & 643 & 1070 & 1050 \\
\hline Ethylene $\left(\mathrm{C}_{2} \mathrm{H}_{4}\right)$ & 3 & 3 & 2 \\
\hline Ethane $\left(\mathrm{C}_{2} \mathrm{H}_{6}\right)$ & 15 & 21 & 8 \\
\hline Acetylene $\left(\mathrm{C}_{2} \mathrm{H}_{2}\right)$ & 8 & 2 & 2 \\
\hline Nitrogen $(\mathrm{N})$ & 60300 & 61100 & 59400 \\
\hline Oxygen + Argon & 31600 & 31600 & 30200 \\
\hline Total dissolved gas & 92602 & 93831 & 90708 \\
\hline Total combustible gas* & 59 & 61 & 58 \\
\hline
\end{tabular}

From this table, it can be observed that gassing tendency of oil samples is not affected by aging rate. The diagnostic for the oil samples predicted by the DGA test method implemented in our software are reported in Tables 5.14 and 5.16.

Table 5.14. DGA after application of Thermal $(20 \mathrm{~A})$ test in the oil samples.

\begin{tabular}{|c|c|c|c|}
\hline & New oil & $500 \mathrm{~h}$ aged oil & $1000 \mathrm{~h}$ aged oil \\
\hline Duval & $\begin{array}{l}\text { Thermal fault } \\
\text { in Oil : } \mathrm{T}>700^{\circ} \mathrm{C}\end{array}$ & $\begin{array}{l}\text { Thermal fault } \\
\text { in Oil }: \mathrm{T}>700^{\circ} \mathrm{C}\end{array}$ & $\begin{array}{l}\text { Thermal fault } \\
\text { in Oil : } \mathrm{T}>700^{\circ} \mathrm{C}\end{array}$ \\
\hline Dörnenburg & No fault & No fault & No fault \\
\hline Roger's & $\begin{array}{l}\text { Low temperature } \\
\text { thermal fault }\end{array}$ & $\begin{array}{l}\text { Low temperature } \\
\text { thermal fault }\end{array}$ & $\begin{array}{l}\text { Low temperature } \\
\text { thermal fault }\end{array}$ \\
\hline
\end{tabular}

As Table 5.14 showed the fault detected by Duval method after application of thermal $(20 \mathrm{~A})$ to new oil, $500 \mathrm{~h}$ and $1000 \mathrm{~h}$ aged oils is thermal fault $\left(\mathrm{T}>700^{\circ} \mathrm{C}\right)$. In the other hand Dörnenburg method displayed there is no fault inside the oil samples and Roger's method indicated low temperature thermal fault in the Labview for all oil samples after application of Thermal (20 A) test.

Fraction of the $500 \mathrm{~h}$ aged oil was reclaimed with Fuller's Earth, degassed before thermal stress application. Tables 5.15 report the dissolved gases extracted from the reclaimed samples after thermal stress application. 
Table 5.15. Dissolved gases extracted from the samples submitted to Thermal stress $(20 \mathrm{~A})$.

\begin{tabular}{|l|c|c|}
\hline Gas & Aged oil $(500 \mathrm{~h})$ & Reclaimed aged oil $(500 \mathrm{~h})$ \\
\hline Hydrogen $\left(\mathrm{H}_{2}\right)$ & 10 & 10 \\
\hline Carbon Monoxide(CO $)$ & 20 & 23 \\
\hline Methane $\left(\mathrm{CH}_{4}\right)$ & 5 & 5 \\
\hline Carbon Dioxide $\left(\mathrm{CO}_{2}\right)$ & 1070 & 1120 \\
\hline Ethylene $\left(\mathrm{C}_{2} \mathrm{H}_{4}\right)$ & 3 & 3 \\
\hline Ethane $\left(\mathrm{C}_{2} \mathrm{H}_{6}\right)$ & 21 & 11 \\
\hline Acetylene $\left(\mathrm{C}_{2} \mathrm{H}_{2}\right)$ & 2 & 2 \\
\hline Nitrogen(N) & 61100 & 60500 \\
\hline Oxygen + Argon & 31600 & 31000 \\
\hline Total dissolved gas & 93831 & 92674 \\
\hline Total combustible gas* & 61 & 54 \\
\hline
\end{tabular}

Out of Table 5.15, it can be observed that the amount of the total dissolved gases and total combustible gases after reclamation decreases.

Table 5.16. DGA after application of Thermal stress $(20 \mathrm{~A})$ to the oil samples.

\begin{tabular}{|l|c|c|}
\hline Duval & \multicolumn{1}{c|}{$500 \mathrm{~h}$ aged oil } & $500 \mathrm{~h}$ Reclaimed aged oil \\
\hline & Thermal fault & Thermal fault \\
\hline Dörnenburg & In Oil $: \mathrm{T}>700^{\circ} \mathrm{C}$ & In Oil $: \mathrm{T}>700^{\circ} \mathrm{C}$ \\
\hline Roger's & No fault & No fault \\
\hline
\end{tabular}

The DGA analysis of aged oil and reclaimed aged oil during 30 minutes thermal test (20 A) are summarized in Table 5.16. In this table it can be observed that DGA reported in Labview was not affected by reclamation of $500 \mathrm{~h}$ aged oil. Determining the DDP and turbidity of the oil specimen after the thermal stress (Figure 5.4), allows assessing the outcome of random secondary chemical reactions between large oil born free radicals. 


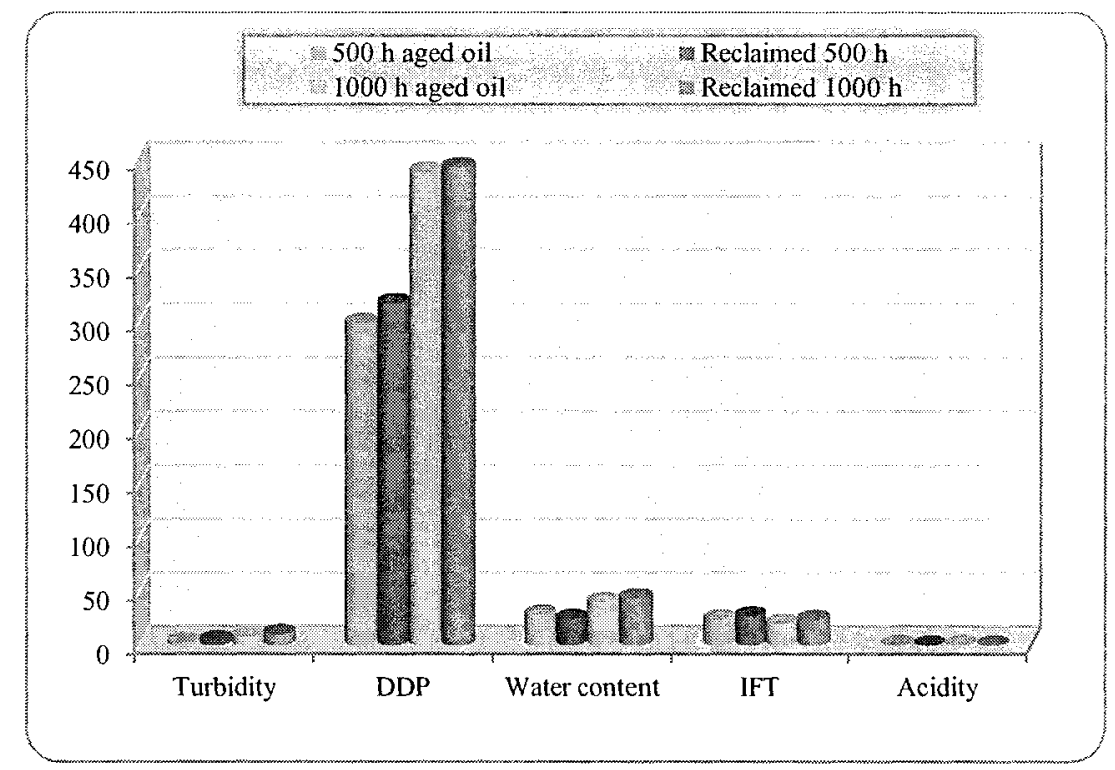

Figure 5.4. Comparative summary of the fluids properties after Thermal test $(20 \mathrm{~A})$.

Data reported in this Figure indicates that, even after reclamation, the removal of dissolved decay products and colloidal suspensions was not complete.

Thermal test repeated (30 minutes) under a constant current of 3 amperes rms for oil samples again. Table 5.17 presents the value of dissolved gas extracted from new oil and aged oil and reclaimed aged oil submitted to 3 amperes.

Table 5.17. Dissolved gases extracted from the samples after thermal stress $(3 \mathrm{~A})$.

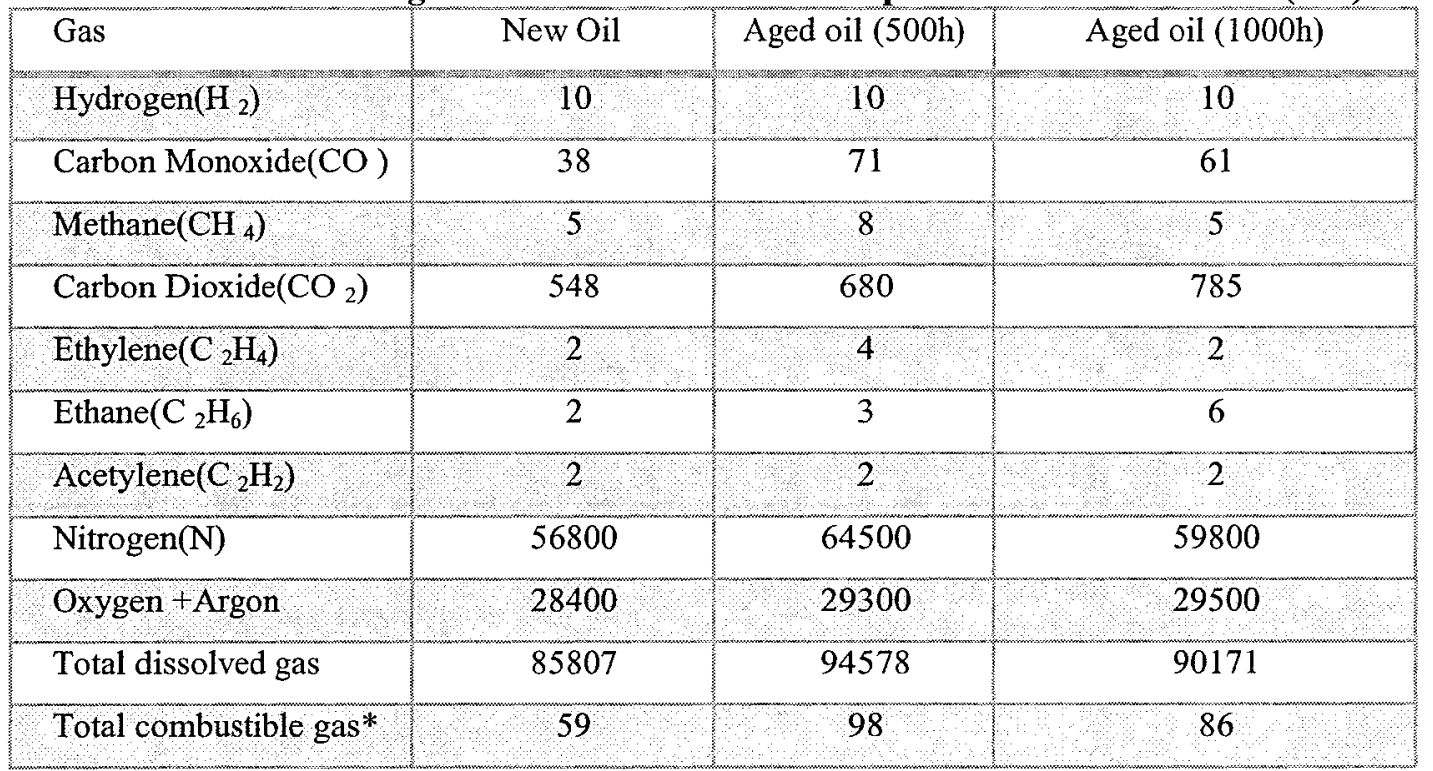


The DGA analysis of data reported in Table 5.17 is shown in Table 5.18. According to this investigation, thermal stress under 3 amperes of constant current is not influenced by aging too.

Table 5.18. DGA assessment's after application of Thermal $(3 \mathrm{~A})$ test in the oil samples.

\begin{tabular}{|c|c|c|c|}
\hline Duval & New oil & Aged oil $(500 \mathrm{~h})$ & Reclaimed aged oil $(500 \mathrm{~h})$ \\
\hline Dörnenburg & Thermal fault & Thermal fault & Thermal fault \\
In Oil $: \mathrm{T}>700^{\circ} \mathrm{C}$ & In Oil $\mathrm{T}<700^{\circ} \mathrm{C}$ & In Oil $: \mathrm{T}>700^{\circ} \mathrm{C}$ \\
\hline Roger's & No fault & No fault & No fault \\
\hline
\end{tabular}

In the Table 5.18 the DGA assessment's by using Duval method in labview indicated there was thermal fault $\left(\mathrm{T}>700^{\circ} \mathrm{C}\right)$ in new oil and $500 \mathrm{~h}$ reclaimed aged oil; meanwhile there was thermal fault $\left(\mathrm{T}<700^{\circ} \mathrm{C}\right)$ inside $500 \mathrm{~h}$ aged oil. In the other way, Dörnenburg method was reported no fault inside the oil samples and Roger's method showed low temperature thermal fault.

Some other properties of oil submitted to thermal stresses $(3 \mathrm{~A})$ are shown in Figure 5.5 .

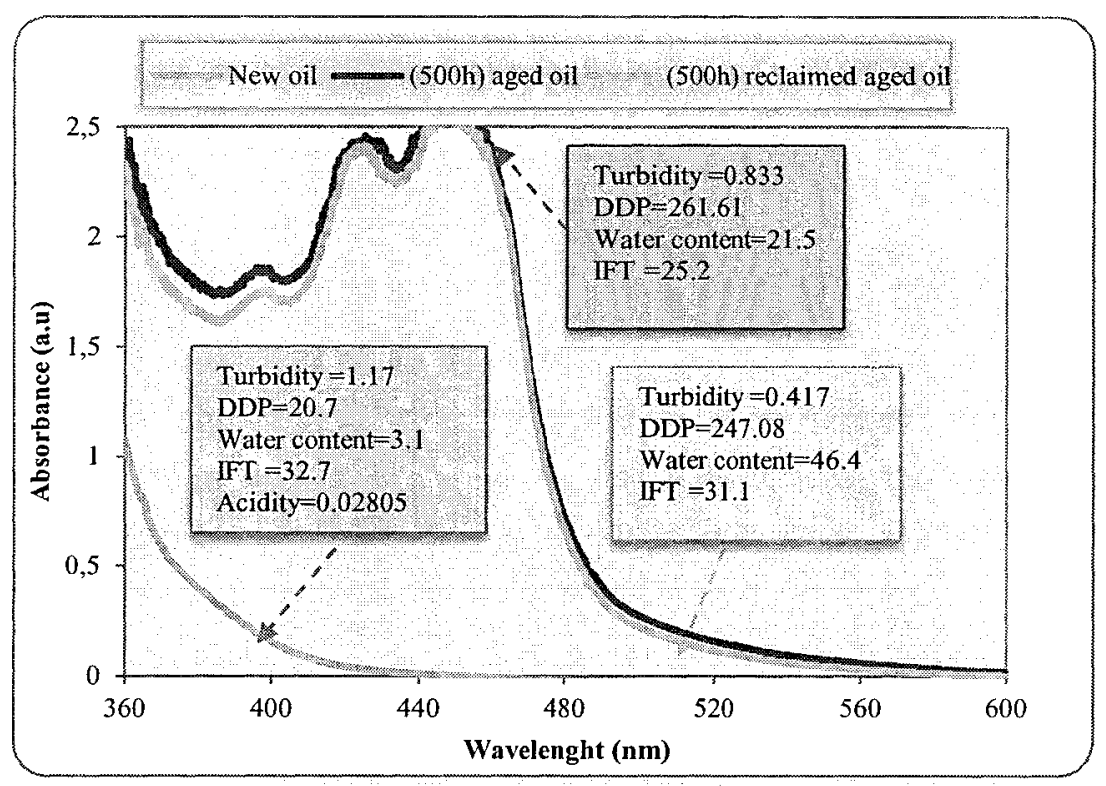

Figure 5.5. Comparative summary of the fluids properties after Thermal test $(3 \mathrm{~A})$. 
Decreasing value of Turbidity and IFT indicate the growth amount of colloidal suspension in the oil specimen under thermal stress. Increasing values of DDP and Water content demonstrate the presence of decay product in oil samples after application of $3 \mathrm{~A}$ constant current.

\subsection{Summary}

Dissolved Gas Analysis (DGA) has now become a standard in the utility industry throughout the world and is considered to be the most important oil test for oil-filled power transformers. This chapter intended to show that the gassing of oil is a complex phenomenon. New oil, aged oil and reclaimed aged oil samples were submitted to thermal and electrical stresses and the dissolved gasses analyzed by GC. By measuring gases dissolved in the oil, maintenance planners can identify the presence of an incipient fault (early warning). The amounts and types of gases found in the oil are indicative of the severity and type of fault occurring in the transformer. The identification and quantification of these gases require the use of sophisticated laboratory equipment and technical skills and therefore can only be conducted by a suitably equipped and competent laboratory.

This chapter provides experimental evidence that the chemical composition of hydrocarbon blend and the oil born decay products are also contributing factors to oil gassing. The influence of oil born decay products onto the diagnostics predicted by some DGA techniques was also emphasized. 


\section{Chapter 6}

\section{Conclusions and Recommendations}




\section{Chapter 6}

\section{Conclusions and Recommendations}

\subsection{Conclusions}

The work, undertaken in this master thesis, aimed at contributing to the improvement of the dissolved gas analysis techniques for power transformers, in order to improve maintenance procedures.

The main objectives of this work consisted in:

- Performing fundamental studies using modern equipments, involving mainly optical diagnostics (turbidity, spectrophotometry,...), electrical and thermal stresses, and physicochemical (Gas chromatography, Acidity, Interfacial Tension: IFT, etc...).

- Understanding the mechanisms involved in the gassing phenomena of insulating fluids.

- Investigating the effectiveness of different diagnostic techniques used in this work, in terms of accuracy to the precise detection of the deterioration of the insulation.

- Investigating the fundamental role played by oil aging byproducts onto the insulating liquids gassing.

All these works might help emphasizing the influence of oil degradation on the DGA interpretation.

For many power equipments such as power transformers, the elaboration of software based diagnosis method and condition-monitoring depends on the implementation of effective maintenance management strategies. In order to study of effectiveness of different diagnostic techniques in oil filled power transformers, three types of diagnostic methods (Duval's triangle, Dörnenburg and Roger's ratios) have been implemented in Labview.

In this work, new and aged oil samples were submitted to stability test, firstly without paper and secondly with paper (oil-paper). The paper in aged oil-paper samples aged at the same time with oil under laboratory condition as well. Oil samples under electrical stress allow us to conclude that:

The theoretical premises that, oil born decay products contribute to the oil gassing is experimentally confirmed under laboratory conditions. The reason why this is important is 
that the dissolved gas-in-oil (DGA) is one of the most widely used diagnostic tools for assessing the condition of electrical transformers and in more recent years load tap-changers and bulk oil circuit. Aged oil and reclaimed aged oil samples were submitted to partial discharge, breakdown and thermal stresses and the dissolved gasses analyzed by chromatography. The obtained results provide experimental evidence that oil born decay products may affect the diagnostics predicted by some DGA techniques.

These investigations may help improving DGA testing techniques due to these very important results, the diagnosis of incipient faults in electric power transformers by DGA should pay particular attention to the gassing tendency of oil under normal conditions operation. Without measuring the gassing pattern of liquid insulation, the transformer fault diagnosis is based solely upon DGA techniques, which can be very misleading.

\subsection{Recommendations}

To improve our basic knowledge in this field, the following recommendations are addressed:

1. The proposed DGA expert system should be extended for other DGA diagnostic methods, to develop an agent-based solution for complete diagnosis and monitoring of power transformers.

2. To study the influence of reclamation process on aged oil-paper (after removing paper) under D6180 stability test.

3. More work is also required to better understand and quantify the impact of oil composition on the DGA tests. Finding a way to better differentiate between the influence of contaminants and oil composition itself will clearly improve the assessment techniques. This seems to be feasible by doing more experiments with different aging rate, under various stresses and different brand of oils to reveal the role played by contaminants onto the DGA test results. 


\section{References}

[1] CIGRE Task force D1.01.10, Ageing of Cellulose mineral-oil insulated transformers, October 2007.

[2] T. O. Rouse "Mineral oil in transformers", IEEE Elec. Insul. Mag., Vol. 14, No. 3, 1998.

[3] Boss P., Lorin P., Viscardi A., et al. "Economical aspects and experiences of power transformer on-line monitoring" CIGRE Session. 2000

[4] I. Fofana, A. Bouaicha, M. Farzaneh, J. Sabau and D. Bussières, "Decay Products in the Liquid Insulation of Power Transformers", IET Electric Power Applications, Vol. 17, Issue 2, pp. 458-464, April 2010.

[5] IEEE C57.104, "IEEE Guide for the Interpretation of Gases Generated in OilImmersed Transformers - Section 1.2 Limitations", 1991.

[6] A. Akbari, A. Setayeshmehr, I. Fofana, H. Borsi and E. Gockenbach, "Intelligent Agent-based System using Dissolved Gas Analysis to Detect Incipient Faults in Power Transformers", IEEE Electrical Insulation Magazine, Vol. 26, No 6, pp. 28-41, November/December 2010.

[7] L. Lewand, "Techniques for Interpretation of Data for DGA from Transformers", IEEE PES Transmission et Distribution" Conference and Exposition, paper F-06, Dallas, May 21-26 2006.

[8] IEEE C37.104, "IEEE Guide for Automatic Reclosing of Line Circuit Breakers for Ac Distribution and Transmission Lines", 08 April 2003.

[9] ASTM D2300-08, "Standard Test Method for Gassing of Electrical Insulating Liquids under Electrical Stress and Ionization (Modified Pirelli Method)", 2008.

[10] Designation: D6180-05, "Standard Test Method for Stability of Insulating Oils of Petroleum Origin under Electrical Discharge", Oct. 2005.

[11] ASTM D 1533, "Standard Test Method for Water in insulating liquids by Coulometric Karl fisher Titration", Book of Standards, Vol. 10.03,2005.

[12] Y. Du, A. V. Mamishev , B. C. Lesieutre, M. Zahn and S. H. Kang," Moisture Solubility for Differently Conditioned Transformer Oils", IEEE Transactions on Dielectrics and Electrical Insulation Vol. 8 No. 5, October 2001. 
[13] Designation: D 974 - 02e1, "Standard Test Method for Acid and Base Number by Color-Indicator Titration1,2", Corrected references in A2.5.1, A2.7.7, and A2.8.1 editorially in October 2003.

[14] Designation: D 971-99a, "Standard Test Method for Interfacial Tension of Oil against Water by the Ring Method", (Reapproved 2004).

[15] Designation: D 6181-03, "Standard Test Method for Measurement of Turbidity in Mineral Insulating Oil of Petroleum Origin”, Oct. 2003.

[16] Designation: D 6802-02, "Test Method for Determination of the Relative Content of Dissolved Decay Products in Mineral Insulating Oils by Spectrophotometry", August 2002

[17] IEEE Std 1291-1993, "IEEE Guide for Partial Discharge Measurement in Power Switchgear, Introduction", IEEE Standards Board (American National Standards Institute) Approved Aug. 30, 1993,

[18] Designation: D877-02, "Standard Test Method for Dielectric Breakdown Voltage of Insulating Liquids Using Disk Electrodes", 2005.

[19] ASTM D3612-02, "Standard Test Method for Analysis of Gases Dissolved in Electrical Insulating Oil by Gas Chromatography (DGA)." approved May 15, 2009.

[20] I. Fofana and J. Sabau, "Application of Petroleum-based oil in Power Transformer", Natural Gas Research Progress, Ch. 6, Nova Science Publishers, Inc., 2008

[21] I. Fofana, "Insulating Oil - Another vital part of transformer body", IEEE DEIS seminar, Montreal-Ottawa chapter, Montreal, June 17, 2010.

[22] I. Fofana, A. Bouaicha, M. Farzaneh, C. Volat, and J. Sabau , "On the Stability of Mineral Insulating Oils under Electrical Stress" IEEE Electrical Insulation Conference (EIC), 2009.

[23] R. Roger, "IEEE and IEC Codes to interpret Incipient Faults in Transformers Using Gas in Oil Analysis" IEEE Trans. Electrical Insulation, Vol. 13, No. 5, pp. 348-354, 1978.

[24] IEEE Power Engineering Society "IEEE Guide of Gases Generated in Oil-Immersed Transformer", 1992.

[25] IEC Publication 599, "Interpretation of the Analysis of Gases in Transformers and Other Oil-Filled Electrical Equipment in Service", First Edition, 1978. 
[26] M. Duval and J. Dukarm, "Improving the Reliability of Transformer Gas-in-Oil Diagnosis", IEEE Electrical Insulation Magazine, Vol. 21, No. 4, July/August 2005.

[27] Pavia, Donald L., Gary M. Lampman, George S. Kritz, Randall G. Engel. "Introduction to Organic Laboratory Techniques" $4^{\text {th }}$ Ed. Thomson Brooks/Cole. pp. 797-817, 2006.

[28] K. Spurgeon, W.H. Tang, Q.H.Wu, Z.J. "Richardson, G.Moss "Evidential Reasoning In Dissolved Gas Analysis For Power Transformers” Ener. Syst. Power 2007.

[29] V. G. Arakelian and I. Fofana, "Physicochemical Aspects of Gassing of Insulating Liquids under Electrical Stress", IEEE Electrical Insulation Magazine, Vol. 25, No. 3, May/June 2009.

[30] J. S. N'Cho, I. Fofana, A. Beroual, T. Aka-Ngnui and J. Sabau, "The gassing Tendency of various Insulating Fluids under Electrical Discharge", IEEE Trans on Diel. and Elec. Insul. Oct. 2011.

[31] R. A. Kurz, J. Leedy, "Stabilization of transformer oil against oxidation old practice with renewed interest for preventive maintenance" IEEE Electrical Insulation Conference and Electrical Manufacturing \& Coil Winding Conference, 1997.

[32] J. S. N'cho, I. Fofana, T. Aka-Ngnui and A. Beroual, "Effect of Exposure to Electrical Discharge on Transformer Oil Properties", International Journal of High Voltage Engineering, Vol. 37, No. 1, pp. 11507-13, November 2011.

[33] P. M. Mitchinson, P. L. Lewin, I. L. Hosier, G. Chen and P. Jarman, "Oil reclamation - just a question of moisture?", IEEE Conf. Dielectr. Electr. Insul. Phenomena, Kansas City, MO, USA, pp. 73-76, 2006.

[34] EL-Sayed M. M. EL-Refaie, Mohamed R. Salem, and Wael A. Ahmed, "Prediction of the Characteristics of Transformer Oil under Different Operation Conditions" World Academy of Science, Engineering and Technology Conference, 2009.

[35] I. Fofana, V. Wasserberg, H. Borsi, and E. Gockenbach, "Challenge of mixed insulating liquids for use in high-voltage transformer, Part 1: Investigation of mixed liquids," IEEE Electr. Insul. Mag., vol. 18, no. 3,pp. 18-31, 2002. 